\title{
SUMINISTRO DE DROGAS A OTRA PERSONA PARA ANULAR SU VOLUNTAD CON FINES DELICTIVOS: ¿MITO O REALIDAD?. LA LLAMADA SUMISIÓN QUÍMICA EN DERECHO PENAL: ESPECIAL REFERENCIAA LOS DELITOS SEXUALES
}

\section{Elena Torres Fernández ${ }^{1}$}

Resumen: Se propone el estudio de la sumisión química, como modalidad comisiva específica y diferenciada entre los delitos de abuso sexual, en el contexto más amplio de infracciones contra la libertad sexual con motivo del amplio debate doctrinal suscitado por la más reciente jurisprudencia en la materia.

Palabras clave: sumisión química, vulnerabilidad química, abusos sexuales, violación.

\section{Recibido: septiembre 2019. Aceptado: noviembre 2019}

1 Catedrática de Derecho Penal. ORCID: https://orcid.org/0000-0002-46313622

Facultad de Derecho. Universidad de Almería. Edificio Departamental de Ciencias Jurídicas (Edif. D), Ctra. Sacramento s/n, La Cañada de San Urbano, CP 04120, Almería. Email: etorres@ual.es 
The administration of drugs with criminal intent in order to override another's will: myth or reality? So-called drug-facilitated crimes in criminal law with special reference to sexual crimes

Summary: This study aims to analyze drug-facilitated crime a specific and differentiated contributory offence among the different other crimes of sexual abuse in the broader context of offenses against freedom of sexual self-determination an in light of the broader doctrinal debate triggered by the most recent jurisprudence in the matter.

Keywords: drug-facilitated crime, drug-facilitated sexual assault, sexual abuse, rape.

\section{Introducción}

A medio camino entre la leyenda urbana y la cifra negra de la criminalidad cabe situar una clase de hechos, que por sus características definitorias, presenta una enorme dificultad para su constatación, conocimiento y eventual determinación y consiguiente exigencia de responsabilidad penal. Se trata de los delitos sexuales cometidos por medio de lo que se ha dado en llamar como sumisión química -en expresión de origen francés-, o en terminología anglosajona drug facilitated sexual assault (DFSA), con la que se viene a referir a delitos acontecidos mediante la administración de alguna sustancia tóxica a la víctima, para disminuir o anular su capacidad para oponerse a un contacto sexual no deseado ${ }^{2}$.

El uso de narcóticos y drogas para afectar a la voluntad de otro con objeto de abusar de él de alguna manera está documentado desde la antigüedad ${ }^{3}$, sin embargo, el interés por

2 Sobre el origen de esa expresión, se sitúa en el año 1982, en la obra de Poyen, B. y otros, "Amnésie et trouble comportametaux d'appareance délictuelle survenue après ingestión de benzodiazepines". Therapie, 37, 1982; citado por CRUZ-LANDEIRA, A.; QUINTELA-JORGE, O.; LÓPEZ-RIVADULLA, M.; "Sumisión química: epidemiología y claves para su diagnóstico". Medicina Clínica, no 20, 2008, p. 783.

3 Sobre el uso de sustancias tóxicas con fines recreativos y también para provocar la sedación con diversos fines ilícitos vid. LÓPEZ-MUÑOZ, F.; 
esta modalidad de actuación sobre otras personas, resurge en tiempos recientes por la facilidad de acceso a las más variadas sustancias, naturales o sintéticas, idóneas para provocar tales efectos en quienes las ingieren y su efectiva utilización con tales finalidades en distintos contextos posibles. Si se atiende a la información disponible en la prensa y medios de comunicación e informativos parece cernirse una considerable incertidumbre sobre tales supuestos, sin embargo y en referencia particular a hechos de índole sexual, los profesionales sanitarios y miembros de fuerzas y cuerpos de seguridad, se enfrentan con relativa frecuencia a situaciones en las que alguna persona, generalmente una mujer joven, presenta significativos indicios de haber sido sometida a un comportamiento de naturaleza sexual sin su consentimiento, en condiciones de las que no es capaz de ofrecer un relato claro, sino basado en recuerdos fragmentarios y confusos, con lo que lejos de la leyenda urbana, más bien se nos muestra como una clase de hechos cuyo esclarecimiento supone un auténtico reto para todos los profesionales implicados, tanto en orden al fin primario de dar una atención adecuada a las víctimas, como también, en orden a conocer las dimensiones reales de tal clase de fenómeno criminológico, de cuya existencia dan cuenta los profesionales de la Medicina Legal quienes con cierta frecuencia se encuentran ante situaciones susceptibles de calificarse como sospechosas de sumisión química ${ }^{4}$.

"Pócimas de bruja en la literatura del Siglo de Oro español: la otra cara de los agentes terapéuticos y psicotrópicos". Revista Medicina, 39. 2017. pp. 332-353. En particular sobre el uso de tóxicos con fines ilícitos, pp. 334, 348-349.

4 Así la Directora del Instituto de Medicina Legal de la provincia de Granada afirma que: "cada uno de los veintidós profesionales del IML ha podido tener sospechas de su uso (sustancias idóneas para anular la voluntad) en al menos dos casos de violación en los últimos cinco años". Ideal, Edición Granada. 11 de diciembre de 2017, p. 2.

Sobre la diferencia entre los casos sospechosos de delito sexual cometido mediante empleo de sustancias tóxicas y el número de denuncias de tales hechos vid. BRAGE CENDÁN, S., "El delito de abuso sexual facilitado por el uso de sustancias químicas". La Ley, 2013. Consultado en BD Doctrina La Ley, ref. 10829/2013. p. 1. 
No menos importante es analizar la respuesta penal a esta clase de hechos, que se incorpora con una regulación específica a partir de la reforma del Código Penal operada por la L. O. $5 / 2010$, de 22 de junio, que incluye la mención entre los abusos no consentidos, de los cometidos anulando la voluntad de la víctima mediante el uso de fármacos, drogas o cualquier otra sustancia natural o química idónea a tal efecto. Y obligado parece reflexionar sobre su concreta regulación legal en el marco del Derecho penal sexual, cuando nos encontramos inmersos en un amplio debate en la doctrina sobre ese conjunto de infracciones, suscitado por la notable cobertura mediática de recientes casos de la escena judicial y el movimiento de contestación social que han alcanzado a suscitar algunas resoluciones judiciales.

El objetivo de este trabajo no es otro que el estudio pormenorizado de las figuras de abusos sexuales cometidos mediante el mecanismo conocido como sumisión química, y su caracterización específica con un perfil diferenciado del resto de las infracciones contra la libertad sexual existentes en la legislación en vigor.

\section{II. ¿Qué es la sumisión química?}

Se considera sumisión química, "la administración de sustancias psicoactivas a una persona con fines criminales o delictivos" $"$. Se trata de administrar subrepticiamente la sustancia a la víctima, a fin de que se pueda manipular su voluntad o modificar su comportamiento, o incluso, provocar su completa inconsciencia. En esta situación, los efectos farmacológicos de la sustancia administrada evitan que la víctima se encuentre en condiciones de prestar su consentimiento válidamente o de oponer resistencia a su atacante ${ }^{6}$. Se trataría de situaciones de inges-

5 TORRES, Y.; ALER, M.; PLATA, A.; DOMÍNGUEZ, A.; SANZ, P., GISBERT, M.; "Factores que afectan al análisis biológico de las muestras de agresiones sexuales". Cuadernos de Medicina Forense, n' 13, 2007, p. 48.

6 GARCÍA-REPETTO, R.; SORIA, M. L.; "Consideraciones toxicológicas sobre supuestos casos de sumisión química en delitos de índole sexual en 
tión de la sustancia sin conocimiento de quien después resulta víctima de un hecho delictivo, con la finalidad de provocar una disminución de su grado de vigilancia, de su estado de consciencia o de su capacidad de juicio. Lo que provoca que la víctima quede dormida, o bien despierta, pero con una capacidad disminuida y bajo control del agresor.

La utilización de esa mecánica comisiva puede ser relevante en una cierta variedad de hechos, así para facilitar la sustracción de objetos, la obtención de consentimiento en operaciones en perjuicio de quien lo otorga, firma de documentos y, con otros fines, la administración de sustancias a niños o incluso a ancianos, para modificar su conducta y recibir de ellos un "buen comportamiento", que se identifica con una menor necesidad de atención por parte de sus cuidadores, pero que puede dar lugar, igualmente, a hechos con trascendencia jurídico penal ${ }^{7}$.

Dentro de los casos que se alcanza a conocer en la práctica forense, se suele distinguir entre:

- supuestos en los que la sustancia idónea para afectar a la capacidad de la víctima ha sido suministrada subrepticiamente por el ofensor, o por un tercero con la finalidad de facilitar la posterior comisión del delito. Sumisión química en sentido propio, también conocido como proactive drug facilitated crime.

- supuestos en los que la situación de incapacidad de la víctima procede del consumo voluntario de las sustancias, que han afectado a su conciencia o a su capacidad de expresar su oposición ${ }^{8}$. Casos de consumo de alcohol, estupefacientes o de medicamentos. Supuestos denominados como vulnerabilidad química,

el sur de España entre los años 2010-2012”. Revista Española de Medicina Legal, n 40, 2014, p. 5.

7 CRUZ-LANDEIRA, A.; QUINTELA-JORGE, O.; LÓPEZ-RIVADULLA, M.; "Sumisión química: epidemiología...cit. p. 784.

8 BECERRA-GARCÍA, J. A.; "Epidemiología de la sumisión química”. Medicina Clínica, ${ }^{\circ}$ 9, 2015, p. 401. 
en terminología de origen francés. O opportunistic drug facilitated crime.

A la clasificación anterior ${ }^{9}$, algunos autores, añaden un tercer grupo de casos cuando a la ingestión voluntaria de alcohol y/o drogas se añade el consumo involuntario de alguna otra sustancia suministrada por un tercero, que genera sinergia entre ambas $^{10}$.

En el ámbito anglosajón, y respecto de los delitos de índole sexual, se utiliza la expresión de drug facilitated sexual assault, (DFSA), para referirse a los delitos de abusos y agresiones sexuales cometidos sobre una víctima que se encuentra bajo los efectos de cualquier sustancia que altere su voluntad. El concepto de DFSA viene acuñado por el Consejo Asesor sobre el abuso de drogas (en Reino Unido), como "todo acto, en el que se realice una actividad sexual, con una persona bajo los efectos de medicamentos, drogas de abuso, independientemente de que la administración haya sido forzada o voluntaria o si se trata de consumo de sustancias de uso legal o sujetas a control"11.

9 Con un criterio diferente, la Agencia Francesa de Seguridad Sanitaria y Productos Sanitarios diferencia:

- sumisión química probada: en la que ha habido agresión o tentativa documentada, y se detecta la presencia de una sustancia psicoactiva mediante un método fiable y la sintomatología y la cronología de los hechos son compatibles con la sustancia indicada.

- sumisión química probable: se sospecha que hubo una agresión, no se dispone de suficiente información clínica o bien los resultados analíticos no son definitivos, o la recogida de muestras tardía, conduce a resultados negativos, o los análisis son incompletos.

- vulnerabilidad química: casos en los que la víctima reconoce el consumo voluntario de medicamentos, sustancias psicoactivas o ambos simultáneamente.

Vid. GARCÍA-REPETTO, R.; SORIA, M. L.; "Sumisión química: reto para el toxicólogo forense", Revista Española de Medicina Legal, n 37, 2011, p. 106.

10 CRUZ-LANDEIRA, A.; QUINTELA-JORGE, O.; LÓPEZ- RIVADULLA, M.; "Sumisión química: epidemiología...cit. p. 784.

11 Sobre el particular, vid. VEGA GARCÍA, A.; "Agresiones facilitadas por el uso de sustancias químicas: retos y realidades". Ponencia presentada en Curso "Agresiones facilitadas por el uso de sustancias químicas". Centro 
Sustancias idóneas son todas aquellas que por sí solas, o mezcladas con otras, como el alcohol tengan como efecto deprimir el sistema nervioso central, o también las estimulantes, con independencia de que sean de tráfico lícito o ilícito, si bien se suele tratar de sustancias con las siguientes características: sustancias de efecto rápido sobre las víctimas y de corta duración, que producen síntomas confundibles con la intoxicación etílica o algún otro trastorno, sustancias de fácil obtención, procedentes del uso farmacológico, ciertos medicamentos de uso común: tranquilizantes, somníferos, antidepresivos, adquiridos tanto bajo prescripción médica, como de venta sin receta. Es conocida la mayor accesibilidad a sustancias de tales características a través de la venta on-line en páginas web en el extranjero de difícil control por las autoridades sanitarias y policiales. Ha de tratarse de sustancias cuya administración pueda pasar fácilmente inadvertida, que se pueda mezclar con la bebida sin que se reconozca su presencia. En el caso de ser administrados mezclados con alcohol, su efecto suele verse potenciado ${ }^{12}$.

Los efectos provocados en la víctima suelen ser: amnesia anterógrada, esto es, la víctima no logra recordar lo sucedido durante el tiempo en él que está bajo los efectos de la sustancia, sedación, disminuyendo la capacidad de atención y respuesta ante un hecho, con distintos grados que van desde la confusión hasta situaciones de sueño profundo, efectos alucinógenos, acompañados de desorientación temporal, lo que resta claridad o coherencia al relato de la víctima sobre lo sucedido, desinhibición, lo que hace que la víctima colabore con el agresor ${ }^{13}$.

de Estudios Jurídicos del Ministerio de Justicia. Madrid, 2013. Consultado en el repertorio jurídico científico del Centro. Accesible en https://www.cejmjusticia.es/. p. 2.

12 CRUZ-LANDEIRA, A.; QUINTELA-JORGE, O.; LÓPEZ- RIVADULLA, M. ; "Sumisión química: epidemiología...cit. p. 785; GARCÍA-REPETTO, R.; SORIA, M. L.; "Sumisión química: reto... cit. p. 107.

13 CRUZ-LANDEIRA, A.; QUINTELA-JORGE, O.; LÓPEZ- RIVADULLA, M. ; "Sumisión química: epidemiología...cit. pp. 785-786; GARCÍA-REPETTO, R.; SORIA, M. L.; "Sumisión química: reto... cit. p. 107; VEGA GARCÍA, A.; "Agresiones facilitadas... cit. pp. 4-6. 
La variedad de sustancias que pueden ser utilizadas para alcanzar tales finalidades es muy amplia, encontrándose entre ellas el alcohol por ser una de las de consumo más extendido y de uso muy generalizado ligado al ocio, medicamentos del grupo de las benzodiacepinas, de fácil acceso por ser de amplia prescripción, entre los que se encuentran alprazolam, clonazepam, triazolam, oxacepam, flunitracepam. Otros productos de uso documentado son los derivados del cannabis, y otras sustancias usadas éxtasis, zolpidem, ketamina, fentanilo, ácido lisérgico, atropina, escopolamina ${ }^{14}$.

Por su facilidad para ser administradas de manera subrepticia, provocar la rápida disminución, o incluso pérdida completa, de la consciencia de la víctima y eliminarse rápidamente del organismo, se ha llegado a hablar de algunas drogas como «drogas de la violación» o «drogas de los violadores», entre las que se cuentan el GHB, la ketamina y el medicamento comercializado como rohypnol. Muy difundido por los medios de comunicación es el posible uso de la llamada burundanga, o escopolamina, sin que se haya alcanzado a documentar su uso en los estudios epidemiológicos disponibles en nuestro país ${ }^{15}$.

14 Sobre las sustancias químicas empleadas para llevar a cabo los ilícitos sexuales vid. Sexual Assaults Facilitated by Drugs or Alcohol. European Monitoring Center for Drugs and Drug Addiction. 2008. pp. 4-5. Consultado en http://www.emcdda.europa.eu/publications/technical-datasheets/ dfsa_en. Último acceso el 01.09.2019.

Se ha documentado la presencia de más de 50 sustancias distintas en esta clase de hechos, GARCÍA-REPETTO, R.; SORIA, M. L.; "Sumisión química: reto... cit. pp. 107-108.

15 En ese sentido XIFRÓ, A.; BARBERÍA, E.; PUJOL, A.; "Sumisión química con finalidad sexual en el laboratorio forense", Revista Española de Medicina Legal, $\mathrm{n}^{\circ}$ 40, 2014, p. 2; GARCÍA-CABALLERO, C.; CRUZ-LANDEIRA, A.; QUINTELA-JORGE, O.; "Sumisión química en casos de presuntos delitos contra la libertad sexual analizados en el Instituto nacional de Toxicología y Ciencias Forenses (Departamento de Madrid) durante los años 2010, 2011 y 2012". Revista Española de Medicina Legal, n 40, 2014, p. 17.

En el sentido de considerar que la prevalencia de casos de sumisión química por las llamadas drogas de la violación, GHB y escopolamina se haya subestimado, por no detectarse en los laboratorios, o por su corta vida me- 
El ácido gammahidroxibutírico conocido como GHB, tiene un efecto muy rápido y corto, $\mathrm{y}$ se elimina rápidamente del organismo, de modo que las concentraciones en sangre se alcanzan en torno a las seis u ocho horas y hasta doce horas en la orina ${ }^{16}$.

La permanencia temporal de las sustancias en el organismo es reducida, en torno a seis horas, por lo que cobra enorme importancia, que la víctima no se demore en acudir a los servicios sanitarios a fin de extraer muestras biológicas útiles para su análisis. La posibilidad de determinar la ingesta de las drogas depende de que la extracción de muestras de sangre o de orina tenga lugar con la mayor proximidad temporal a los hechos, y en todo caso, no más allá de cuarenta y ocho horas ${ }^{17}$. A pesar del valor que tiene la obtención de muestras con rapidez, la celeridad en la denuncia no suele ser común debido al estado de aturdimiento y confusión en el que se encuentran las víctimas tras el hecho, así como no menos frecuente, los sentimientos de vergüenza y culpabilidad que experimentan tras lo sucedido ${ }^{18}$.

La comprobación de las sustancias se hace a través de muestras de sangre o de orina, si bien cuando ello no es posible por haber transcurrido tiempo suficiente para que no queden restos de tóxico en ese tipo de muestras, cabe la posibilidad del análisis del muestras de cabello, pues permite confirmar la exposición a una droga semanas después de su consumo, a través del análisis segmental, para fijar la fecha posible del consumo

dia. Vid. BURILLO-PUTZE; G.; LÓPEZ-HERNÁNDEZ, A.; EXPÓSITORODRÍGUEZ, M.; DUEÑAS-LAITA, A.; "Sumisión química, oportunista o premeditada". Medicina Clínica, no 140, 2013, p. 139.

16 CRUZ-LANDEIRA, A.; QUINTELA-JORGE, O.; LÓPEZ- RIVADULLA, M. ; "Sumisión química: epidemiología...cit. p.786.

17 Se refieren a la necesidad de recoger las muestras de sangre y orina con prontitud antes del transcurso de 6 horas como elemento clave para poder obtener evidencias analíticas de un delito sexual facilitado por drogas, vid. GARCÍA CABALLERO, C.; QUINTELA, J.; CRUZ LANDEIRA, A.; "Alleged-drug facilitated sexual assault in a Spanish population sample". Forensic Chemistry, 2017. p. 65.

18 CRUZ-LANDEIRA, A.; QUINTELA-JORGE, O.; LÓPEZ- RIVADULLA, M.; "Sumisión química: epidemiología...cit. p. 786. 
considerando el crecimiento del pelo, si bien, es un tipo de análisis costoso, que requiere de un equipamiento tecnológico y capacitación, que no está disponible en todos los laboratorios de investigación forense ${ }^{19}$.

La dificultad que entraña la investigación en estos casos hace que el enfoque de la actuación de los profesionales de la Medicina Legal deba orientarse a demostrar la existencia de un delito sexual, basándose para ello en el conjunto de circunstancias relativas a los hechos, y no ceñirse únicamente, a la constatación del tóxico empleado. El estudio del caso debe ser completo basándose en la víctima, el agresor y los hechos, dirigido a esclarecer el hecho sucedido ${ }^{20}$.

Los datos existentes sobre delitos sexuales cometidos mediante sumisión química son muy escasos, si bien los distintos estudios disponibles cifran la prevalencia de entre un seis por ciento y un treinta y cuatro por ciento de casos compatibles con la sumisión química de entre el conjunto de delitos sexuales investigados ${ }^{21}$. Y la constatación de la administración de una sustancia tóxica a la víctima es tan residual, que puede afirmarse que mientras que la sumisión química en sentido estricto es un

19 Con detalle sobre el análisis toxicológico de muestras vid. VEGA GARCÍA, A.; "Agresiones...cit. pp. 7-31.

20 LORENTE ACOSTA, M.; "Actuación médico forense en la atención a las víctimas de agresiones sexuales por sumisión química". Ponencia presentada en Curso "Agresiones facilitadas por el uso de sustancias químicas". Centro de Estudios Jurídicos del Ministerio de Justicia. Madrid, 2013. Consultado en el repertorio jurídico científico del Centro. Accesible en https:// www.cej-mjusticia.es/. pp. 17-18.

21 GARCÍA REPETTO, R.; SORIA, M. L.; "Consideraciones toxicológicas sobre supuestos casos de sumisión química en delitos de índole sexual en el sur de España entre los años 2010-2012". Revista Española de Medicina Legal, $\mathrm{n}^{\mathrm{o}} 40,2014$, quienes señalan un $6,12 \%$ de casos sospechosos de sumisión química, en 73 casos de 1194 denunciados; GARCÍA CABALLERO, C.; CRUZ LANDEIRA, A.; QUINTELA JORGE, O.; "Sumisión química en casos de presuntos delitos contra la libertad sexual analizados por el Instituto Nacional de Toxicología (Dpto. Madrid) durante los años 2010, 2011 y 2012". Revista Española de Medicina Legal, n 40, 2014, quienes señalan un $35 \%$ un total de 107 casos del conjunto de 306 hechos estudiados. 
fenómeno relativamente infrecuente y con una caracterización criminológica muy particular, la llamada vulnerabilidad quími$c a$, como situaciones en las que un tercero aprovecha la situación de otra persona, que tiene sus capacidades mermadas por el consumo voluntario de alcohol, drogas o medicamentos, es un fenómeno muy frecuente, hasta el punto de poder ser calificado como un problema de salud pública, que puede ser especialmente significativo en sectores de población muy jóvenes que practican el consumo de alcohol en grandes cantidades en periodos de tiempo muy cortos binge drink, con graves intoxicaciones etílicas en determinados contextos de ocio ${ }^{22}$.

En el contexto más amplio de la preocupación que suscitan los distintos aspectos del consumo de drogas, diversos organismos internacionales se han interesado por este aspecto concreto dentro de esa compleja problemática, y han dirigido su atención hacia el uso de drogas como medio para facilitar la comisión de delitos sexuales. Así, en el año 2007, la Asamblea del Consejo de Europa, emitió la Recomendación 1777, sobre agresiones sexuales ligadas a las "drogas de la violación”, en la que insta al Comité de Ministros a elaborar un enfoque europeo armonizado para atender ese fenómeno, tanto a nivel técnico y científico, pero también, sancionador y judicial. En concreto exige a los Estados miembros del Consejo de Europa, entre otras medidas, dirigidas a atender adecuadamente a las víctimas de esta clase de hechos, la de "revisar la legislación relativa a la violación y la agresión sexual para incluir una infracción sin distinción de sexo y añadir, cuando aún no se haya hecho, una disposición para prever que la víctima debe haber tenido "la li-

22 XIFRÓ, A.; BARBERÍA, E.; PUJOL, A.; "Sumisión química con finalidad... cit. p. 2.

Confirman la mayor cantidad de casos de vulnerabilidad química sobre la sumisión química PANYELLA CARBÓ, M. N.; AGUSTINA, J. R.; "Sumisión química vs. vulnerabilidad química: análisis criminológico de los delitos sexuales facilitados por el uso de sustancias psicoactivas a partir de una muestra de sentencias". Revista Española de Investigación Criminológica, $\mathrm{n}^{\mathrm{o}} 17,2019$, p. 5 . 
bertad y la capacidad de dar su consentimiento" a las relaciones sexuales e incluir los casos de violación entre esposos" ${ }^{23}$.

La Comisión de Estupefacientes de Naciones Unidas emitió la Resolución 53/7, sobre Cooperación internacional para combatir la administración subrepticia de sustancias psicoactivas relacionadas con la agresión sexual y otros actos delictivos, entre otras medidas, "llama la atención a los Estados hacia la posibilidad de que en su legislación nacional o sus directrices pertinentes se prevean circunstancias agravantes en los casos en que se administren subrepticiamente sustancias psicoactivas para cometer una agresión sexual". El mandato de la Comisión de Estupefacientes exige que la administración de tales sustancias agrave los delitos sexuales cometidos sin consentimiento del ofendido. Mandato, que puesto en relación con la legislación española, y habida cuenta la variedad de subgrupos de tipos penales contra la libertad sexual, no parece tener definida una forma inequívoca de darle cumplimiento ${ }^{24}$. Y ello es así, porque en el Código penal español, los delitos sexuales cometidos sin consentimiento de la víctima se articulan en dos grupos, agresiones cometidas mediante violencia o intimidación, y abusos sexuales, cometidos sin consentimiento y sin que medie violencia ni intimidación ${ }^{25}$.

23 Texto adoptado pro la Asamblea Parlamentaria el 22 de enero de 2007.

24 Sobre el tratamiento legal de la sumisión química en los delitos sexuales en otros ordenamientos jurídicos vid. con detalle PANYELLA CARBÓ, M. N.; AGUSTINA, J. R.; "Los delitos sexuales facilitados mediante el uso de sustancias psicoactivas: análisis jurídico-penal de la denominada "sumisión química". Revista Política Criminal. (en prensa) Texto facilitado por cortesía de sus autores. pp. 26-35 del manuscrito.

25 En sentido muy crítico con la tipificación finalmente adoptada por el legislador español, vid. SANCHO DE SALAS, M.; XIFRÓ COLLSAMATA, A.; BERTOMEU RUÍZ, A.; ARROYO FERNÁNDEZ, A.; "Sumisión química con finalidad sexual: nuevos aspectos legales". Revista Española de Medicina Legal, n 38,2012 . p. 41. 


\section{La sumisión química como medio comisivo en los delitos de abusos sexuales}

En el texto del Código Penal aprobado en el año 1995 no se incluyó la mención expresa de la administración de fármacos o drogas a fin de materializar un contacto sexual sin oposición de la víctima. En ausencia de una regulación expresa de tal medio comisivo para llevar a cabo un ilícito sexual, la jurisprudencia que trató ese tipo de hechos en unos casos optó por situarlo dentro de las agresiones sexuales, particularmente la violación ${ }^{26}$, y en otros, entre los abusos sexuales sobre víctima privada de sentido $^{27}$. Otros autores apuntan a que en defecto de regulación expresa podría encontrarse implícita en la modalidad de abuso de prevalimiento ${ }^{28}$.

No es hasta la modificación legal llevada a efecto por la L. O. 5/2010, de 22 de junio, cuando el legislador decide incluir expresamente la mención del "uso de fármacos, drogas o cualquier otra sustancia natural o química idónea para anular la voluntad de la víctima" en el artículo 181.2, entre los delitos de abuso sexual. La información disponible en la tramitación parlamentaria sobre las razones para su incorporación es bastante escasa. Dicho artículo no aparece recogido en el Anteproyecto de Ley, ni tampoco en el texto del Proyecto presentado a las Cortes. Su inclusión en la tramitación tuvo lugar por la enmienda número 350 de las presentadas en el Congreso de los Diputados, cuyo contenido fue finalmente admitido; si bien su texto defi-

26 Durante la vigencia del Código Penal texto refundido de 1973, posterior a la reforma por L. O. 3/1989, tal supuesto de víctima privada de sentido se encuadraba en la violación, así las STS de 28 de octubre de 1991, STS de 15 de febrero de 1994 y, con posterioridad también aplican el delito de violación, la STS 22 de mayo de 2006, STAP Islas Baleares de 7 de junio de 2006, la STAP de la Coruña de 16 de mayo de 2011.

27 SSTS de 23 de enero de 2004, 22 de septiembre de 2004, 22 de octubre de 2008, STAP Santa Cruz de Tenerife de 17 de abril de 2012.

28 Vid. de esa opinión MORALES PRATS, F.; GARCÍAALBERO, R.; Comentarios a la Parte Especial del Derecho Penal. 10a. Ed. Cizur Menor, 2016. Consultada en BD Thompson Proview, texto del fichero generado p. 17. 
nitivo difiere ligeramente del inicial, pues se refería a que tales sustancias "anulen o disminuyan la voluntad de la víctima". En la escueta justificación para su inclusión se indica que "se contempla un tipo agravado (sic) de la pena para aquellos casos en los que existe un dolo específico en la comisión delictiva del abuso sexual”29.

Es de ese modo en el que tiene lugar la regulación de la llamada sumisión química, como una modalidad de abuso sexual de las que por disposición legal se considera expresamente como modalidades de abusos no consentidos, y equiparada a los abusos que se ejecuten sobre personas privadas de sentido o personas de cuyo trastorno mental se abusare.

\section{Marco legal de delitos contra la libertad sexual}

Numerosas han sido las reformas legales que han incidido sobre el Título VIII del Libro segundo del Código penal desde la aprobación de su texto allá por el año $1995^{30}$. Reformas con un contenido dispar, que lejos de suponer la progresión en línea de mejora continuada para la definición más precisa de los ataques contra la libertad sexual, bien jurídico individual que es objeto de protección de este conjunto normativo, en no pocos casos suponen el retorno a regulaciones de marcados tintes moralizantes,

29 Boletín Oficial de las Cortes Generales. Congreso de los Diputados. IX. Legislatura. 18 marzo de 2010. p. 156.

30 Desde la aprobación del Código Penal en el año 1995, cinco han sido las reformas que han afectado a este grupo de delitos. La primera tuvo lugar por L. O. 11/1999, la segunda y tercera por las L. O. 11/2003, de 29 de septiembre y L. O. 15/2003, de 25 de noviembre. La cuarta por la L. O. 5/2010, de 22 de junio y la quinta, y última hasta la fecha, la introducida por la L. O. $1 / 2015$, de 30 marzo. Reformas justificadas en varios casos por la necesidad de acomodar la legislación interna a las directrices de armonización sugeridas en el contexto de la Unión Europea, y cuya plasmación en el derecho interno, supera en no pocas ocasiones tanto los mínimos de intervención penal, como los marcos punitivos, lo que ha determinado la progresiva ampliación y endurecimiento de este particular conjunto normativo.

En particular sobre la tendencia seguida por esas reformas MARTÍN LORENZO, M.; Ley Orgánica, 5/2010. Memento Experto Francis Lefevre. Madrid, 2010. pp. 89-90. 
más próximas a la tutela de una determinada moral sexual colectiva, no necesariamente coincidente con la de una confesión religiosa $^{31}$, pero sí la corrección auspiciada por los sectores que aspiran a convertirse o se erigen, como los nuevos gestores de la moral social ${ }^{32}$. Sin ánimo de exhaustividad, y por poner algunos ejemplos, podría mencionarse en ese sentido apuntado, la tipificación de hechos de lesividad más que dudosa en relación con la pornografía infantil, tal es el caso de la creación de material que represente de manera visual a un menor o persona con discapacidad o de imágenes realistas de un menor o de los órganos sexuales de un menor, del artículo 189.1 b) subapartados a) y d), material que puede haber sido íntegramente elaborado con programas o aplicaciones de diseño o tratamiento de imágenes sin participación de personas reales, pornografía tecnológica, mediante la formación íntegramente artificial de imágenes de niños, ${ }^{33}$ o la elevación de la edad para poder consentir en comportamientos de índole sexual a los dieciséis años ${ }^{34}$.

31 Así "las arpías de la legislación moralizante o meramente simbólica parecen perseguir al Derecho penal donde quiera que vaya" vid. CANCIO MELIÁ, M.; "Una nueva reforma de los delitos contra la integridad sexual". La Ley Penal. $\mathrm{n}^{\circ} 80,2011$. pp. 2-3. Texto edición digital consultado en la BD La Ley Doctrina.

De las reformas de signo moralizante, señala RAMÍREZ ORTÍZ, que se debe evitar "que las valoraciones culturales sobre la sexualidad pesen hasta el punto de que la propia tipificación constituya una amenaza para el bien jurídico que se afirma defender". Vid. "Sociedad en red, igualdad, proceso y derecho penal. La sentencia de la Manada". Jueces para la Democracia. $\mathrm{n}^{\circ}$ 92, 2018. p. 18.

32 Sobre el particular vid. SILVA SÁNCHEZ, J. M.; La expansión del Derecho penal. Aspectos de la Política criminal en las sociedades postindustriales. $3^{\mathrm{a}}$ Ed. Buenos Aires, 2011. pp. 66-68.

33 Sobre el particular vid. BOLDOVA PASAMAR, M. A.; "El nuevo concepto de pornografía infantil: una interpretación realista". Revista Penal, $\mathrm{n}^{\circ} 38$, 2016 , p. 65-66, quien propone una interpretación restrictiva del concepto de pornografía infantil, al tiempo que cuestiona la deriva hacia un derecho penal basado en la peligrosidad presunta de cierta clase de hechos.

34 Sobre esta cuestión vid. DÍAZ Y GARCÍA CONLLEDO, M., TRAPERO BARREALES, M. A., "La "edad de consentimiento sexual" en la reforma del Código Penal de 2015". Estudios de Derecho Penal. Homenaje al Prof. Miguel Bajo. Coord. S. Bacigalupo Sagesse. Madrid, 2016. pp. 872-893. 
El derecho penal sexual vigente se caracteriza por ser una regulación que separa las tipologías delictivas construidas sobre el empleo de distintos medios comisivos en orden a ejecutar el acto de índole sexual, así como sobre la diferente significación lesiva del hecho de naturaleza sexual practicado, disponiendo la imposición de penas más graves dentro de cada tipología delictiva, cuando el ataque consiste en las modalidades, que suponen las intromisiones sexuales más intensas y vejatorias para el sujeto pasivo, sobre la distinción del acceso carnal y hechos equiparados, y actos de contenido sexual, que en cierta medida se definen por exclusión de lo que es acceso carnal o afines ${ }^{35}$.

El grado de precisión alcanzado por la legislación en la definición de diferentes ilícitos en orden a poder ofrecer una respuesta punitiva proporcionada a su gravedad ha sido considerado por la doctrina como "un signo de civilización y de eficacia" ${ }^{36}$. Y en ese sentido, la clasificación de infracciones sexuales incorporada a la legislación se ha valorado como una muestra de definición técnica en orden a dar una respuesta penal lo más y mejor ajustada posible a la valoración de los hechos.

De acuerdo con lo expuesto se pueden encontrar varios grupos de infracciones con distintos niveles de antijuridicidad. El primero de ellos representado por los delitos de agresiones sexuales del capítulo I, y como modalidad específica de ellas, la violación, que se cometen doblegando la voluntad contraria de la víctima al hecho sexual utilizando al efecto violencia o intimidación. Un segundo grupo de infracciones, los abusos sexuales del capítulo II, caracterizados por llevar a cabo el hecho sin violencia, sin intimidación y sin consentimiento de la víctima. En esta categoría, se incluyen también ciertos supuestos que por

35 Clasificación de las infracciones en atención a la cualidad de los medios típicos por los que se somete a la víctima, que ha sido valorada como un acierto, vid. en ese sentido, GARCÍA ALBERO, R.; MORALES PRATS, F.; Comentarios a la Parte Especial ... cit. p. 2 texto del fichero generado.

36 En palabras de LASCURAÍN SÁNCHEZ, J. A.; Vid. "Las huellas de La Manada". El Cronista del Estado Social y Democrático de Derecho. $\mathrm{n}^{\circ}$ 77, 2018, p. 19. 
disposición legal tienen la categoría de abusos no consentidos, a saber, los cometidos sobre personas privadas de sentido y sobre personas de cuyo trastorno mental se abusare, y los supuestos de anulación de la voluntad de la víctima mediante el uso de sustancias idóneas a tal efecto. Un tercer grupo serían los abusos sexuales cometidos con consentimiento viciado, por obtenerse éste bien con prevalimiento de una situación de superioridad manifiesta que coarte la libertad de la víctima, o en este último caso, cuando se trate de menores de más de dieciséis y menos de dieciocho años del artículo 182. Elemento implícito a todas estas infracciones de los capítulos I y II del título VIII es que la víctima sea mayor de dieciséis años, por debajo de esa edad los delitos de naturaleza sexual, infracciones como abusos, agresiones y otras figuras específicas diferenciadas -así, entre ellas, el ciberacoso con fines sexuales- se integran en capítulo aparte, el II bis.

Las agresiones sexuales son delitos en los que se actúa en contra de la voluntad de la víctima. Y se definen por el empleo de violencia o intimidación dirigidas a vencer la oposición de la víctima imponiéndole los deseos del autor. Se trata de hechos en los que el autor impone su actuación a la víctima. Ambos conceptos, violencia o intimidación, han quedado fijados con precisión en una dilatada jurisprudencia ${ }^{37}$. Tanto una como otra, no han de ser extremas, absolutas o irresistibles, sino que de ambas se exige que sean suficientes y eficaces para vencer la oposición de la víctima de acuerdo con el contexto y las circunstancias en las que tiene lugar el hecho ${ }^{38}$. Sin prescindir de que lo que singulariza a la agresión sexual es que "se actúa contra la voluntad

37 Vid. entre otras las SSTS de 3 de octubre de 1997, 28 de abril de 1998, de 14 de junio de 2004, 22 de diciembre de 2008, de 7 de marzo de 2013, de 10 de julio de 2013, 28 mayo 2015, 21 enero de 2016, 18 de julio de 2017.

38 Vid. En ese sentido CUERDA ARNAU, M. L.; "Agresión y abuso sexual: violencia o intimidación vs. consentimiento viciado". La Manada. Un antes y un después en la regulación de los delitos sexuales en España. Valencia, 2018. p. 107, p. 111. 
de la víctima" ${ }^{\prime 39}$. Han de tener cierta entidad y ser adecuadas para el fin del contacto sexual que se pretende. Sin que la resistencia de la víctima sea un elemento típico, sino únicamente la falta de consentimiento $^{40}$.

En particular, respecto de la violencia, se ha señalado que es la que se emplea para someter a la víctima, y puede ser "una violencia inicial de escasa entidad (por ej., una bofetada), con la amenaza de que a mayor resistencia que oponga la víctima, mayor será la violencia física que empleará el delincuente. Es evidente que, en estos casos, aunque la violencia no llegue a desplegarse en toda su intensidad, la amenaza en sí de una mayor violencia es más que suficiente para ser considerada de la misma gravedad y magnitud que la violencia irresistible misma. No es necesario, por tanto, una resistencia continuada y heroica del sujeto pasivo, que puede, apenas comiencen los primeros actos de violencia, aceptar la relación sexual que se le pide, entre otras cosas, para evitar males mayores a su integridad física o incluso su propia muerte". ${ }^{41}$

En cuanto a la intimidación, se exige que sea "suficiente, dadas las circunstancias concurrentes, resulte bastante para someter o suprimir la voluntad de resistencia" ${ }^{\prime 2}$. Al efecto de valorar si la intimidación ejercida es suficiente debe tenerse en cuenta las características objetivas del hecho ejecutado y las circunstancias personales de la víctima, entendiendo desde un punto de vista neutral y considerando todos los datos fácticos, que si la víctima hubiera llegado a alcanzar el convencimiento de la inutilidad de continuar la oposición, pues de ello se podría producir un mayor daño, y en virtud de ello accede a lo preten-

39 CUERDA ARNAU, M. L.; “Agresión y abuso sexual... cit. p. 120.

40 CUERDA ARNAU, M. L.; “Agresión y abuso sexual... cit. pp. 113-114 y 119.

41 MUÑOZ CONDE, F.; "La vinculación del juez a la ley y la reforma de los delitos contra la libertad sexual. Algunas reflexiones sobre el caso "La Manada". Revista Penal, no 43, 2019. p. 292, De VICENTE MARTÍNEZ, R.; "El delito de violación: problemas que plantea su vigente redacción". La Manada. Un antes y un después en la regulación de los delitos sexuales. Dirs. Acale Sánchez, Faraldo Cabana, Valencia, 2018. p. 186. 
dido por el autor, la intimidación ejercida tiene el carácter de suficiente ${ }^{43}$.

Como se ha señalado, en la definición de los ilícitos de cada subgrupo de infracciones se establece un tipo con los comportamientos sexuales más intrusivos o insidiosos, que son los consistentes en "acceso carnal por vía vaginal, anal o bucal o introducción de miembros corporales u objetos por alguna de las dos primeras vías", hecho que cuando tiene lugar con violencia o intimidación tiene la consideración legal en derecho vigente de delito de violación. No siempre ha sido así, pues en la redacción originaria del año 1995, desapareció ese nomen iuris, lo que tuvo una acogida dispar entre la doctrina, siendo recuperada más tarde la denominación de violación para las agresiones sexuales de mayor potencialidad lesiva, sin que, por otra parte, dicho delito volviera a coincidir con lo que en larga trayectoria histórica iniciada por el Código penal de 1848 había venido siendo calificado como tal ${ }^{44}$, pues de su contenido habían salido en el Código de 1995, los supuestos de acceso carnal con menores por debajo de un límite de edad -doce años-, personas privadas de sentido y de cuyo trastorno mental se abusara, los llamados supuestos de violación presunta, en los que la ausencia de consentimiento de la víctima venía equiparado punitivamente al empleo de violencia o intimidación, supuestos que en el texto

42 CUERDA ARNAU, M. L.; “Agresión y abuso sexual... cit. p. 112.

43 En ese sentido, CANCIO MELIÁ, M.; "Los delitos de agresiones sexuales, abusos sexuales y acoso sexual". La Ley, 2001, Consultado en BD La Ley Digital. Ref. 21816/2001. p. 3; GAVILÁN RUBIO, M., "Agresión sexual y abuso con prevalimiento: análisis de la reciente jurisprudencia". Revista de Derecho, Empresa y Sociedad. $\mathrm{n}^{\circ}$ 12, 2018, p. 94; CUERDA ARNAU, M. L.; "Agresión y abuso sexual... cit. pp. 112-113, p. 130; MUÑOZ CONDE, F.; "La vinculación del juez... cit. p. 293.

44 Sobre el delito de violación a lo largo de la historia de nuestro derecho penal codificado vid. FARALDO CABANA, P.; "Evolución del delito de violación en los códigos penales españoles. Valoraciones doctrinales". $L a$ Manada. Un antes y un después en la regulación de los delitos sexuales. Dirs. Acale Sánchez, Faraldo Cabana, Valencia, 2018, pp. 31-70. 
originario del Código penal de 1995 encontraron su acomodo en el marco de los delitos de abusos sexuales ${ }^{45}$.

Parece existir cierto consenso sobre lo acertado de la consideración como violación del acceso carnal por vía vaginal, anal o bucal, cualquiera que sea el sexo del sujeto activo y el pasivo, admitiéndose todas las combinaciones posibles (relación sexual hetero u homosexual) ${ }^{46}$. Cualquiera de tales hechos tiene objetivamente una inequívoca significación sexual, que de ser realizados en contra de la voluntad de otra persona, los convierte en graves ataques la libertad de quien los padece ${ }^{47}$. Y, de acuerdo con ello, la consideración de la libertad sexual como bien jurídico protegido de titularidad individual no permite restricciones en cuanto a la posibilidad de considerar tutelada a cualquier persona, cualquiera que sea su sexo y su orientación sexual. No se

45 Valora positivamente este aspecto de la regulación CANCIO MELIÁ, M.; "Los delitos de agresiones sexuales... cit. p. 8, pues considera que: "no merece el mismo tratamiento jurídico penal el comportamiento de quien mantiene un contacto sexual con una persona incapaz de autodeterminarse en el ámbito sexual (sea porque de hecho está privada de sentido o porque no tiene la madurez necesaria para hacerlo) que el de quien coarta la libertad de otro obligándolo por violencia o intimidación a soportar actos sexuales".

46 Sobre los accesos por distintas vías reconducibles a alguna forma de penetración la STS de 19 de noviembre de 2002 señala que: "el concepto de penetración tiene un fundamento normativo de acuerdo en el cual se da cuando la acción violenta pueda ser considerada como una grave afrenta a la intimidad sexual del sujeto pasivo"; ese concepto presupone que el acceso carnal y la penetración supongan la introducción del órgano sexual masculino que puede realizarse en las cavidades que el tipo penal reseña, vagina, acceso carnal propiamente dicho, o bucal o anal, rellenándose la tipicidad tanto cuando se penetra como cuando se hace penetrar, es decir, tanto cuando un sujeto activo realiza la conducta de penetrar, como cuando es la víctima la que es obligada a realizar la conducta contra su voluntad, con violencia o intimidación o sin su consentimiento o con un consentimiento viciado, presuponiendo la introducción del órgano sexual masculino en alguna de las cavidades típicas".

47 Da cuenta de la opinión contraria, la de considerar "indebido lugar preponderante del acceso carnal dentro del derecho penal sexual" y "focalizado en la penetración como elemento central para graduar la gravedad de la conducta", sostenido por determinados sectores, vid. RAMÍREZ ORTÍZ, "Sociedad en red...cit. p. 18. 
desconoce que en la realidad criminológica los delitos contra la libertad sexual, y en sus modalidades más graves ${ }^{48}$, de agresión sexual son cometidos de manera mayoritaria por hombres, sin embargo, no se justifica una tipificación que traslade esa diferencia de los sujetos a la regulación penal ${ }^{49}$.

Más dudas suscita la consideración de violación de los hechos equiparados al acceso carnal, que se han incorporado al concepto de violación ${ }^{50}$. Considerado fuera de la tipicidad penal, de manera unánime, queda la introducción de objetos o miembros corporales por vía bucal, pues se trata de un hecho objetivamente carente de connotaciones sexuales, por lo que su realización no es idónea para materializar la lesión de la libertad sexual ${ }^{51}$. En cambio, las opiniones se dividen cuando de la introducción de objetos por vía vaginal o anal se trata. En mi opinión, el carácter de órgano sexual de la vagina, así como la usual utilización del ano como vía para la práctica sexual, hacen que la introducción de objetos por cualquiera de esas dos vías alcance a tener una significación sexual indiscutida, que convierta a esa clase de hechos en agresión sexual equiparable a la

48 Los últimos datos disponibles en el Instituto Nacional de Estadística son los correspondientes al año 2017, siendo el número de condenas totales por delitos sexuales un total de 332, de las cuales 331 son a hombres. Siendo hombres el total de los condenados por delitos de agresión sexual 98 y por violación 5. Datos consultados en www.ine.es.

49 Vid. en ese sentido CANCIO MELIÁ, M.; "Delitos contra la libertad e indemnidad sexuales". Memento Penal. Edición actualizada a julio de 2019 consultada en BD QMementix. p. 1 del fichero generado.

50 El Convenio de Estambul sobre prevención y lucha contra la violencia contra las mujeres y prevención de la violencia doméstica define como violación en su artículo 36.1 a) la penetración vaginal, anal u oral no consentida, con carácter sexual, del cuerpo de otra persona con cualquier parte del cuerpo o con un objeto.

Cuestionable es la mención de la posibilidad de considerar violación la introducción de miembros corporales -distintos del órgano sexual masculinou objetos por vía bucal por carecer de connotaciones sexuales.

51 Vid. Por todos, GÓMEZ TOMILLO, M.; "Derecho penal sexual y reforma legal. Análisis desde una perspectiva político criminal”. RECPC, 2005, pp. 7-8. 
violación, cuando se realiza en contra de la voluntad del sujeto y con recurso a la violencia o intimidación. La introducción de objetos en tales circunstancias alcanza a menoscabar la libertad sexual con intensidad equiparable al acceso carnal en sentido estricto, e incluso superar su potencial vejatorio por lo degradante que tal experiencia puede resultar para el sujeto pasivo ${ }^{52}$. Y las mismas razones expresadas para la introducción de objetos cabe argumentar en relación con la modalidad de introducción de miembros corporales ${ }^{53}$.

Como delito de agresión sexual se define el hecho de atentar contra la libertad sexual de otra persona en el artículo 178, y que con discutible técnica legislativa, basada en la referencia al atentado contra el bien jurídico, viene a incluir, hechos cometidos con violencia o intimidación, que por exclusión no pueden ser los expresamente tenidos en cuenta el artículo 179, y para constituir delito han de tener una significación sexual objetivable, exigiéndose un mínimo de contacto corporal ${ }^{54}$. Para concluir con la regulación de las agresiones sexuales, se incluye un conjunto de tipos agravados sobre la concurrencia de determinadas circunstancias sobre la base de diferentes fundamentos agravatorios en el artículo 180 del $\mathrm{CP}^{55}$.

52 De VICENTE MARTÍNEZ, R.; "El delito de violación... cit. pp. 198-203.

53 En sentido contrario de la extensión de los hechos equiparados al acceso carnal, y en particular, respecto de la introducción de objetos por vía vaginal o anal vid. entre otros, GIMBERNAT ORDEIG, E.; "Prólogo a la décima edición". Código Penal. Tecnos. 25a . ed. Madrid, 2017. p. 51; CANCIO MELIÁ, M.; "Los delitos de agresiones sexuales ... cit. pp. 5-6; GÓMEZ TOMILLO, M.; "Derecho penal sexual... cit. p. 7.

54 En sentido contrario, de entender que dado que el tipo exige el ataque a la libertad sexual, y ésta puede verse lesionada por hechos que no necesariamente impliquen un contacto sexual entre el agresor y su víctima, caben hechos en los que no haya contacto vid. en ese sentido CANCIO MELIÁ, M.; "Los delitos de agresiones sexuales ... cit. pp. 3-4.

55 Artículo 180. 1. "Las anteriores conductas serán castigadas con las penas de prisión de cinco a diez años para las agresiones del artículo 178, y de doce a quince años para las del artículo 179, cuando concurra alguna de las siguientes circunstancias: 
Un segundo grupo de infracciones contra la libertad sexual son los abusos sexuales del capítulo II, del título VIII, definidos por tener lugar sin violencia, sin intimidación y sin consentimiento, o equiparado a la falta de consentimiento, el consentimiento viciado. $\mathrm{Y}$ entre los abusos sin consentimiento, los que reciben esa consideración por disposición legal expresa en el artículo 181.2. Y de igual manera, con distinción de si el acto ejecutado es acceso carnal o equiparados, o abuso genérico.

No es en absoluto fácil caracterizar el ámbito aplicativo del abuso sexual, al venir definido en negativo, por la ausencia de violencia o intimidación, y por la falta de consentimiento. Se suele incluir en la modalidad del tipo básico los contactos sexuales sorpresivos, en los que la víctima es sometida a actos de contenido sexual sin haber tenido ocasión de reaccionar. Hechos consistentes en tocamientos, abrazos, caricias eróticas, que en todo caso han de tener una cierta entidad objetiva para ser merecedores de la pena con la que se amenaza en el tipo penal, para evitar el riesgo de castigar meros excesos o faltas de consideración, sin suficiente potencial lesivo para el bien protegido. Esta exigencia es aún más necesaria si se tiene en cuenta la desaparición de la falta de vejación injusta de carácter leve del

$1^{\mathrm{a}}$. Cuando la violencia o intimidación ejercidas revistan un carácter particularmente degradante o vejatorio.

$2^{\mathrm{a}}$. Cuando los hechos se cometan por la actuación conjunta de dos o más personas.

$3^{\mathrm{a}}$. Cuando la víctima sea especialmente vulnerable, por razón de su edad, enfermedad, discapacidad o situación, salvo lo dispuesto en el artículo 183.

$4^{\mathrm{a}}$. Cuando para la ejecución del delito, el responsable se haya prevalido de una relación de superioridad o parentesco, por ser ascendiente, descendiente o hermano, por naturaleza o adopción, o afines con la víctima.

$5^{\text {a }}$. Cuando el autor haga uso de armas u otros medios igualmente peligrosos, susceptibles de producir la muerte o alguna de las lesiones previstas en los artículos 149 y 150 de este Código, sin perjuicio de la pena que pudiera corresponder por la muerte o lesiones causadas.

2. Si concurrieren dos o más de las anteriores circunstancias, las penas previstas en este artículo se impondrán en su mitad superior". 
artículo 620.2 del Código Penal, que permitía incardinar en su ámbito de aplicación los hechos más leves ${ }^{56}$.

El Tribunal Supremo construye la aplicación del delito de abuso sexual sobre tres elementos: "a) un elemento objetivo, de contacto corporal, tocamiento impúdico o cualquier otra exteriorización o materialización con significante sexual, b) tal elemento objetivo o contacto corporal puede realizarse tanto ejecutándolo el sujeto activo sobre el cuerpo del sujeto pasivo, como con maniobras que éste realice sobre el cuerpo de aquel, siempre que éstas se impongan a personas incapaces de determinarse libremente en el ámbito sexual, c) un elemento subjetivo o tendencial, que tiñe de antijuridicidad la conducta, expresado en el clásico "ánimo libidinoso" o propósito de obtener una satisfacción sexual a costa de otro" 57 . La pena prevista para este delito es de prisión de uno a tres años o multa de dieciocho a veinticuatro meses, que permite al juzgador escoger dentro de un margen bastante amplio la consecuencia punitiva en concordancia a la considerablemente variable gravedad de los hechos que pueden alcanzar a integrar esa tipicidad, procediendo sin más considerar la atipicidad e impunidad de los hechos más nimios.

Más difícil aún es caracterizar el abuso sexual sin consentimiento cuando consista en acceso carnal o modalidades equiparadas. Pues parece que el intento de llevar a cabo cualquiera de las modalidades de penetración típica relevante o de introducción de objetos o miembros corporales habrá de suscitar al menos una mínima oposición o rechazo de quien lo sufre, de manera que quedará exteriorizada su negativa al contacto se$\mathrm{xual}^{58}$. Por lo que se muestra muy ardua la definición de su ám-

56 Sobre las consecuencias de la desaparición de la falta del artículo 620.2 del Código Penal en la redefinición del ámbito típico de los delitos de abusos sexuales genéricos vid. PÉREZ ALONSO, E.; "Concepto de abuso sexual: contenido y límite mínimo del delito de abusos sexuales”. In Dret. $\mathrm{n}^{\circ} 2019$, pp. 22 y ss.

57 Así las SSTS 612/2016, de 8 de julio, 2311/215 de 22 de abril y 55/2012, de 7 de febrero.

58 En ese sentido vid. CANCIO MELIÁ, M.; "Los delitos de agresiones sexuales...cit. p. 10; De VICENTE MARTÍNEZ, R.; "El delito de violación... 
bito típico. Se ha sugerido como supuesto incardinable el que se trate de personas que están imposibilitadas para poder oponer resistencia, por ejemplo una persona paralítica, lo que lo asemejaría a la modalidades del artículo 182.2 de supuestos a los que legalmente se les atribuye la consideración de no consentidos, si bien con el matiz diferencial, de que las personas del 182.2 no están en condiciones de capacidad para decidir, mientras que el tetrapléjico no tiene capacidad para poder resistir y poder hacer valer su voluntad contraria.

En el momento de aprobación del Código penal los supuestos de abusos no consentidos por disposición legal, como una presunción de que no ha habido consentimiento válido ${ }^{59}$, eran los de personas privadas de sentido y personas de cuyo trastorno mental se abusare ${ }^{60}$. Privada de sentido está la persona inconsciente, y por ello incapaz de prestar consentimiento, pero cabe incluir también situaciones en las que la persona, sin faltarle totalmente la conciencia, está seriamente afectada en sus facultades de atención, vigilancia o concentración necesarias para autodeterminarse. Mientras que la persona de cuyo trastorno mental se abusa, no se trata de situaciones en las que propiamente no puede consentir, sino que el ordenamiento no le reconoce eficacia al consentimiento así otorgado. De acuerdo con la regulación legal, queda claro que no es suficiente con

cit. p. 188, quien afirma: "si la conducta sexual se lleva a cabo sin forzar la voluntad de la víctima, sin violencia ni intimidación, ni sin consentimiento, no parece posible que un abuso pueda consistir en penetración vaginal, anal o bucal o introducción de objetos o miembros por vía anal o vaginal".

También señala la dificultad de precisar el ámbito de aplicación del 181.1 de hechos definidos íntegramente en términos negativos, sin consentimiento, sin violencia, sin intimidación, SAN MIGUEL BERGARECHE, M. N., “¿Juzgar y castigar con perspectiva de género?”. Boletín Comisión Penal. n 10, vol., II., 2018. p. 26.

59 BRAGE CENDÁN, S., "El delito de abuso sexual... cit. p. 3.

60 De "abusos por incapacidad situacional para consentir los califica" CANCIO MELIÁ, M.; "Una nueva reforma... cit. p. 6. En otra publicación los califica de "abusos sexuales sobre personas incompetentes", vid. "Delitos contra la libertad e indemnidad sexuales...cit. p. 32. 
que la persona padezca una anomalía psíquica, sino que es necesario que el autor conozca esa anomalía y la aproveche para acceder al contacto sexual. Con ello, se admite la existencia de un margen legal en el que es posible la práctica sexual de personas discapacitadas, cuando no hay un aprovechamiento de su discapacidad $^{61}$.

Desde 2010, se incluye entre estas modalidades del artículo 181.2 del Código Penal la anulación de la voluntad de la víctima mediante el uso de sustancias idóneas para ello. La situación de incapacidad para determinarse en la que se encuentra la víctima por efecto del tóxico suministrado es similar a la de quien está privado de sentido, y por ello el legislador ha considerado que ésta era la ubicación adecuada para esta nueva modalidad.

Sin embargo la regulación de los supuestos de incapacidad para consentir por falta de la aptitud y las condiciones necesarias para poder hacerlo ha suscitado no pocas críticas desde el momento mismo de la aprobación del Código penal. Se argumenta que, en tales casos, no es necesario hacer uso de fuerza o intimidación para vencer la oposición de la víctima al contacto sexual con los medios comisivos más graves de las agresiones, por lo que la inclusión de tales supuestos entre los abusos, castigados con una pena significativamente menor, redunda en una menor protección no justificada de una categoría de sujetos ${ }^{62}$. Los mismos argumentos valen para las personas que están incapacitadas para oponer resistencia (paralítico), supuestos de los que se ha afirmado que: "resulta cuanto menos cuestionable que un hecho de tal naturaleza merezca o necesite una sanción penal más reducida, al menos en su límite máximo, que la que corresponde a un delito de violación" ${ }^{63}$. Y tampoco se encuentra

61 vid. por todos, BRAGE CENDÁN, S., "El delito de abuso sexual... cit. p. 10.

62 En ese sentido, FARALDO CABANA, P.; RAMÓN RIBAS, E.; "La sentencia de la Manada y la reforma de los delitos de agresiones y abusos sexuales”. Dirs. Acale Sánchez, Faraldo Cabana, Valencia, 2018, p. 291.

63 Vid. GÓMEZ TOMILLO, M.; "Derecho penal sexual... cit. pp. 3-4. 
mucho sentido a la menor protección de los discapacitados de cuyo trastorno se abusa ${ }^{64}$.

En particular, de la anulación de la voluntad mediante la administración de sustancias se ha destacado su idoneidad para impedir completamente la oposición de la víctima, por lo que son varios los autores que consideran un supuesto más cercano y por ello equiparable valorativamente al empleo de violencia, habiéndose llegado a considerarla como un puñetazo químico, que la haría merecedora de un tratamiento punitivo equivalente al de las agresiones sexuales, y la violación, en su caso ${ }^{65}$.

En los abusos sexuales de prevalimiento del artículo 181.3, como el propio tipo penal exige ha de mediar consentimiento, que se ha obtenido prevaliéndose de una situación de superioridad ${ }^{66}$. Y como señala Cuerda Arnau, "la superioridad a la que se refiere el artículo $181.3 \mathrm{CP}$ no es la que intimida al sujeto pasivo hasta el punto de doblegar su voluntad, sino la que conduce a formarla conforme a los deseos del agresor"67. En este caso, la víctima forma su voluntad conforme a los deseos del autor por efecto condicionante de la situación de superioridad. La voluntad de la víctima está condicionada o coartada,

64 En sentido crítico de la regulación como abusos sexuales no consentidos del artículo 181.2 de supuestos que hasta la aprobación del Código penal de 1995 tenían un tratamiento equiparado a las agresiones sexuales, y en su caso, la violación: vid. las valoraciones tempranamente vertidas por CARMONA SAlGADO, C., Curso de Derecho Penal Español. Parte Especial I. Madrid, 1996. pp. 321-323, quien afirma respecto de tales sujetos que: "el interés tutelado en ambos supuestos típicos no es la libertad en sentido estricto, sino la intangibilidad o indemnidad sexual de los sujetos comprendidos en ellos, quienes, incapaces desde un punto de vista juridico penal de ejercer válidamente dicho interés, merecen en consecuencia una especial protección por parte de este sector del Ordenamiento", p. 322. (cursiva añadida)

65 En ese sentido, vid. entre otros LASCURAIÍN SÁNCHEZ, J. A.; "Las huellas... cit. pp. 18-19; MUÑOZ CONDE, F.; "La vinculación del juez... cit. p. 294; SANCHO DE SALAS, M.; XIFRÓ COLLSAMATA, A.; BERTOMEU RUIZ, A.; ARROYO FERNÁNDEZ, A.; "Sumisión química... cit. p. 41.

66 CUERDA ARNAU, M. L.; “Agresión y abuso sexual... cit. pp. 126-127.

67 CUERDA ARNAU, M. L.; “Agresión y abuso sexual... cit. p.131. 
pero no está anulada ${ }^{68}$. Dado que se trata de supuestos en los que se consiente, aunque con una voluntad viciada, hay autores que no encuentran sentido a castigar de manera distinta el hecho en función de si ha consistido en acceso carnal o equiparados, u otro tipo de acto de significación sexual, pues en ambos casos se produce idéntica afectación de la libertad en el proceso de formación de su decisión cualquiera que sea el tipo de contacto sexual objeto de requerimiento por parte del autor ${ }^{69}$. La superioridad exigida para poder apreciar el tipo penal se entiende en un sentido de posición desigual de los sujetos, cercana a la intimidación o la coacción ${ }^{70}$.

La última modalidad de abuso sexual es la de abuso fraudulento, interviniendo engaño, y desde la reforma de 2015, equiparado a él, el abuso de una posición de reconocida confianza, autoridad o influencia sobre la víctima. Hechos que son relevantes en relación a personas mayores de dieciséis años y menores de dieciocho. También distingue entre abuso genérico 182.1 y abuso consistente en acceso carnal y equiparados 182.2. Si bien, no se alcanza a entender cómo en el caso de que el he-

68 Sobre la distinción entre la intimidación de la agresión sexual y la superioridad del abuso sexual de prevalimiento vid. FARALDO CABANA, P.; "Hacia una reforma de los delitos sexuales con perspectiva de género". pp. 268-269; JERICÓ OJER, L.; "Perspectiva de género, violencia sexual y Derecho penal". Ambos capítulos del libro Mujer y Derecho penal ¿necesidad de una reforma desde una perspectiva de género?. Dir. A. Monge Fernández. Barcelona, 2019. pp. 310-311.

69 Así señala CANCIO MELIÁ que: "El desvalor de la conducta a la que se refiere la agravación está en que incide de modo negativo en la formación de la voluntad de la víctima. Pero no queda claro por qué razón esta afectación a la libre toma de decisiones de la víctima debe ser considerada más grave cuando la víctima acepte mantener los contactos del 179. Dicho de otro modo: es evidente que éstos constituyen una intromisión más grave (art. 178 en relación al 179) cuando son impuestos a la víctima, pero cuando lo que se ve afectado es la formación de la voluntad de la víctima, la incidencia en esta es la misma con independencia de cual sea el contacto sexual asumido. Lo contrario significa asignar a esta modalidades de contacto sexual un desvalor objetivo per se que no les corresponde". Vid. "Los delitos de agresiones sexuales... cit. p. 10.

70 En ese sentido LASCURAÍN SÁNCHEZ, J. A.; "Las huellas... cit. p. 21. 
cho cometido sea el acceso carnal o asimilados, y tratándose de menores de dieciséis y diecisiete años, y la similitud del abuso de la posición de confianza o influencia sobre el menor de edad, lleve aparejada una pena inferior a la del abuso de prevalimiento del 181.3, de cuatro a diez años de prisión, frente a la de dos a seis años del abuso fraudulento del 182.1 del Código Penal ${ }^{71}$.

Para los abusos de prevalimiento del artículo 181.3 y los fraudulentos del 182, se dispone la aplicabilidad de las circunstancias agravantes de que la víctima sea especialmente vulnerable, por razón de su edad, enfermedad, discapacidad o situación circunstancia $3^{\mathrm{a}}$, y prevalimiento de una relación de superioridad o parentesco, por ser ascendiente, descendiente o hermano de la víctima circunstancia $4^{\text {a }}$ del artículo 180 del Código Penal.

Por último, hay que señalar que, elemento implícito a todos los delitos de agresiones sexuales del capítulo I y de abusos sexuales del capítulo II, es que la persona agredida sea mayor de dieciséis años, pues la protección penal de los menores de esa edad frente a ilícitos sexuales se lleva a cabo en los delitos del título II bis artículos 183 a 183 quater, en un conjunto normativo procedente de la reforma de la L. O. 5/2010, que mereció la valoración positiva de la doctrina por venir a resolver las dificultades que se habían evidenciado para su adecuada protección desde la insatisfactoria regulación establecida por el texto original del Código penal del año 1995, si bien la nueva redacción no está exenta a su vez de cuestiones criticables. Así, la nueva regulación viene a establecer un trato unificado a conductas que ya contenía el Código penal, a las que eleva las penas y completa la extensión del elenco de cualificaciones, en la línea de dar un tratamiento singularizado a las infracciones cometidas sobre menores de edad. Por su parte, la fijación del límite de edad re-

71 Sobre el sentido de esa infracción, y en particular, la distorsión punitiva en relación al abuso de prevalimiento vid. SANZ CANTERO, J. E.; Sistema de Derecho Penal Español. Parte Especial. Madrid, 2016, p. 257. 
levante para el consentimiento sexual de los menores es elevado a dieciséis años en la L. O. 1/2015 $5^{72}$.

\section{El delito de abuso sexual cometido anulando la vo- luntad de la víctima mediante el uso de fármacos}

La especificidad de la sumisión química, como medio comisivo basado en la administración de sustancias idóneas para afectar a las condiciones psíquicas necesarias para decidir respecto del ejercicio de la propia sexualidad merece una valoración positiva, pues expresa el interés del legislador por dar una adecuada respuesta a las particularidades, que configuran lo característico de tales situaciones, más allá de los posibles efectos o rasgos comunes con otros conceptos empleados por el legislador. Se trata de hechos en los que sin alcanzar a producirse una pérdida de conciencia propia de la "privación de sentido", se anula la capacidad necesaria para determinarse autónomamente en materia sexual. Discutible es, sin embargo, la concreta configuración legal elegida por el legislador.

El empleo de sumisión química al efecto de facilitar un contacto sexual no querido con otra persona ha sido considerado por el legislador como una modalidad de abuso sexual con la consideración ex lege de no consentido, con el tratamiento de presunción legal de que en tales casos, no existe consentimiento $^{73}$. De la escueta dicción legal "anulando la voluntad de la víctima" se infiere la necesidad de que la sustancia haya sido administrada a la víctima, de manera que sólo están incluidos en el tipo penal los supuestos de sumisión química en sentido estricto o las también llamadas agresiones proactivas, en las que la si-

72 Sobre los aspectos generales de esa reforma Vid. CUGAT MAURI, M., "Delitos contra la libertad e indemnidad sexuales". Comentarios a la Reforma Penal de 2010. Valencia, 2010. pp. 229 y pp. siguientes, TAMARIT SUMALLA, J. M. ; "Los delitos sexuales. Abusos sexuales. Delitos contra menores (arts. 178, 180, 181, 183, 183 bis)". La Reforma Penal de 2010: análisis y comentarios. Cizur Menor, 2010. pp. 166-168.

73 Considera correcta la opción legal de tener por no manifestado el consentimiento en estos casos por considerarlo irrelevante, QUERALT JIMÉNEZ, J. J.; Derecho Penal Español. Parte Especial. 7ª Ed. Valencia, 2015, p. 225. 
tuación de incapacidad para determinarse ha sido provocada por quien luego va a mantener el contacto sexual, o por otra persona actuando en colaboración con él. Se trataría de los supuestos de suministrar a la víctima de manera subrepticia alguna sustancia, de manera que la merma de facultades es debida a la actuación de quien después se aprovecha de esa incapacidad para actuar sobre la víctima ${ }^{74}$. De acuerdo con ello, quedarían fuera del supuesto los casos, más numerosos si se atiende a los datos recopilados en los estudios empíricos, en los que el alcohol, cannabis, hachís, medicamentos u otras drogas han sido consumidos voluntariamente por quien después es objeto de algún contacto sexual no deseado, calificados en el contexto médico legal como vulnerabilidad química, que darían lugar a las agresiones conocidas como agresiones oportunistas.

La construcción de este tipo penal tiene lugar sobre dos elementos: por un lado el empleo de fármacos, drogas o cualquier otra sustancia natural o química idónea para anular la voluntad y por otro, el efecto del consumo de la sustancia de anulación de la voluntad.

Las sustancias referidas, vienen finalmente completadas por una cláusula de cierre "sustancia idónea para anular la voluntad", por lo que el conjunto final de sustancias posibles va a ser muy variado, incluyendo tanto de origen natural, como sintético, siempre que tengan entre sus propiedades la aptitud para anular la voluntad.

Los estudios de casos constatan la detección de más de cincuenta clases de sustancias diferentes en los hechos sospechosos de sumisión química. Cuando son usadas tendencialmente, los agresores las seleccionan con las siguientes características: de acción rápida y corta duración en el organismo, que provoque síntomas inespecíficos fácilmente confundibles con el consumo

74 Vid. en ese sentido BARRUTIA SOLIVERDI, B:, "Estudio de la sumisión química". La Ley Penal. n 117, 2015. Consultado en la BD La Ley Digital. pp. 4-5 texto impreso de la edición digital. BRAGE CENDÁN, S., "El delito de abuso sexual... cit. p. 5; CUGAT MAURI, M., "Delitos contra la libertad...cit. p. 226. 
de alcohol, que se puedan suministrar a la víctima sin generar sospecha, añadiéndolas a una bebida. Y que produzcan en quien las ha consumido los siguientes efectos: amnesia anterógrada, que afecta a los hechos acaecidos desde que se ha tomado la sustancia, sedación, efectos alucinógenos, y desinhibición, lo que convierte a la víctima en colaboradora con su agresor.

El segundo elemento es la anulación de la voluntad. Sobre este elemento no existe consenso en su caracterización. Así hay quienes entienden que la anulación exige una incapacidad absoluta de consentir, "sin que baste una mera limitación de la voluntad si ésta (la víctima) conserva cierta capacidad de comprensión del hecho y control de sí misma", sólo así se entiende la equiparación legal a la privación de sentido y al abuso del trastorno mental que sufre la víctima ${ }^{75}$. No obstante, siendo la finalidad del agresor la de mantener un contacto sexual que no es deseado por la otra persona, la voluntad a la que se refiere el texto legal debe entenderse como la capacidad para autodeterminarse en el ámbito sexual, y por tanto, el efecto sobre la persona, el de no encontrarse en las condiciones necesarias para decidir sobre tales aspectos. Y la afectación de la capacidad para determinarse con autonomía en el ámbito sexual admite distintos niveles de afectación, por lo que no se precisa una anulación total al punto del estado de inconsciencia, sino que es suficiente una afectación considerable de capacidad con disminución del grado de vigilancia, del estado de conciencia y de la capacidad de juicio, de manera que no pueda oponerse eficazmente a los deseos del agresor ${ }^{76}$.

Cuando la incapacidad para autodeterminarse es debida al consumo voluntario de alcohol, drogas o medicamentos por

75 En esa línea TAMARIT SUMALLA, J. M.; "Los delitos sexuales...cit. p. 169. Autor que propone que, en los casos en los que la anulación no implique la pérdida total de la capacidad para determinarse sexualmente, sino sólo la merma o la afectación considerable sea la calificación alternativa en tales casos la de abuso sexual de prevalimiento del artículo 181.3 del Código Penal.

76 Exige el mismo efecto de "no estar en disposición de oponerse a los deseos del asaltante" ORTS BERENGUER, E.; Derecho Penal. Parte Especial. Coord.. J. L. González Cussac. 5ª Ed. Valencia, 2016, p. 191. 
parte de la víctima, situaciones denominadas como vulnerabilidad química, no integra el supuesto de hecho del subtipo del artículo 181.2 "anulando la voluntad", pues éste requiere que la pérdida de capacidad haya sido provocada por quien después abusa de la otra persona en tal situación, o en su caso, por un tercero partícipe en el delito. Tales supuestos de vulnerabilidad química pueden encontrar acomodo en alguna de las otras dos modalidades de abusos no consentidos, bien en la de privación del sentido, cuando en su origen esté en la intoxicación por alcohol o drogas consumidas previamente, y que sin haber sido provocado por el sujeto que realiza el hecho sexual, si es conocido y aprovecha el estado en que se encuentra la víctima para llevar a cabo el contacto sexual ${ }^{77}$. La privación de sentido, como señala una reiterada jurisprudencia no ha de ser absoluta hasta el punto de la inconsciencia, sino que cabe apreciarla en supuestos en los que el sujeto conserva la conciencia, y basta una disminución psíquica que haga que la víctima se encuentre inerme a los requerimientos sexuales ajenos ${ }^{78}$.

Desde la incorporación de esta modalidad de abuso sexual al Código penal han sido varias las ocasiones en las que la jurisprudencia ha tenido la posibilidad de pronunciarse sobre la aplicación de este delito ${ }^{79}$, si bien, en un grupo significativo de casos no alcanza a considerar fuera de toda duda razonable,

Lo define como "notable alteración de su capacidad para decidir libremente sobre la relación sexual a la que el autor le aboca" GARCÍA RIVAS, N.; Derecho Penal Español. Parte Especial I. Dir. F. J. Álvarez García. Valencia, 2011, p. 617.

77 En ese sentido las SSTAP de Alicante de 6 de octubre de 2016 y 7 de junio de 2018.

78 En esa línea las SSTS de 28 de octubre de 1991, 15 de febrero de 1994, 28 de julio de 2009, entre otras.

79 Se condena por abusos sexuales en los que ha mediado la administración subrepticia de sustancias tóxicas a la víctima, STAP de Barcelona de 11 de junio de 2015, STAP de Madrid, de 20 de julio de 2015, STAP de Alicante de 4 de marzo de 2016, se administra benzodiacepina, STAP de Lérida de 24 de noviembre de 2016 se administra doxilamina conocida por el nombre comercial de dormidina, STAP de Barcelona de 15 de mayo de 2017; STAP de Valencia de 19 de febrero de 2018. 
que se tratara de hechos ocurridos sin consentimiento o con anulación de la voluntad de la víctima ${ }^{80}$. De especial interés es la STAP de Santiago de Compostela de 6 de marzo de 2014 en la que, aunque considera probada la administración de drogas para facilitar el contacto sexual con la víctima, finalmente condena por delito de violación sobre la acreditación de la violencia ejercida para llevar a cabo el acceso carnal, violencia que alcanzó a provocar unas lesiones del artículo 147.2 del Código penal. Y considera que el delito de violación alcanza a consumir y desplazar la aplicación del delito de abuso sexual del artículo 181.2.

\section{Excurso: la administración de drogas a otras per- sonas en otros contextos delictivos}

Como quedó expuesto al inicio de este trabajo, la administración de sustancias idóneas para disminuir el nivel de atención y conciencia de otra persona con el fin de cometer un hecho ilícito no es un medio comisivo en exclusiva del contexto de los ilícitos sexuales, si bien, es en ese ámbito donde quizás su empleo es más conocido y suscita más alarma. Por su idoneidad para dejar al ofendido en una situación de merma de su capacidad psíquica en orden a expresarse, formar su voluntad, decidir y poder oponerse frente a actuaciones que le afectan, es una forma de proceder muy versátil y que puede resultar apta para integrarse en la dinámica comisiva de diferentes ilícitos.

La jurisprudencia ha tenido ocasión de pronunciarse sobre casos de delitos contra el patrimonio mediante apoderamiento de objetos, para facilitar la sustracción se administra a la víctima alguna sustancia, que le provoca somnolencia, para poder hacerse con sus objetos o efectos de valor, cuando no está consciente. En ausencia de una regulación expresa de la sumisión química como medio comisivo en este conjunto delictivo, la jurisprudencia aplica el delito de robo, por considerar que ese hecho como empleo de violencia para llevar a cabo la sustrac-

80 STAP de Tarragona 19 de noviembre de 2014, STAP de Salamanca de 27 de abril de 2015, STAP de Barcelona de 13 de enero de 2014, STAP de Zaragoza de 23 de septiembre de 2016, STAP de Madrid de 27 de octubre de 2017. 
ción. Si la disminución de conciencia de la víctima tiene lugar por su previo consumo voluntario, en tal caso no se aprecia la existencia de violencia, y sería de aplicación la calificación de hurto $^{81}$. Lo que determina una significativa diferencia de pena$\operatorname{lidad}^{82}$.

También se ha documentado casos sospechosos de suministrar drogas a otra persona para obtener sus tarjetas bancarias y usarlas en cajeros, sin que el ofendido logre recordar cómo el autor accedió a sus tarjetas para poder utilizarlas ${ }^{83}$.

Otros contextos pueden ser la administración a menores de edad sustancias sedantes para tranquilizarlos o condicionar su comportamiento en el sentido de requerir una menor atención de los adultos responsables, lo que puede dar lugar a la causación de lesiones en los niños, especialmente si son de muy corta edad. Así por ejemplo los hechos enjuiciados en la sentencia de la AP de la Coruña de 11 de noviembre de 2015. O la administración de esas mismas sustancias para provocar inconsciencia y en ese estado facilitar la posterior causación de la muerte, como sucede en la sentencia mencionada.

81 Con detalle, vid. FOMBELLIDA VELASCO, L.; "Consideraciones sobre el delito sexual facilitado por sustancias". La Ley, 2013. Consultado en BD La Ley Digital, 2013, p. 3 del documento generado; BARRUTIA SOLIVERDI, B:, "Estudio de la sumisión... cit. p. 3; SANCHO DE SALAS, M.; XIFRÓ COLLSAMATA, A.; BERTOMEU RUIZ, A.; ARROYO FERNÁNDEZ, A.; "Sumisión química... cit. p. 41.

Sobe la sospecha de sumisión química en delitos contra el patrimonio vid. BERTOMEU RUÍZ, A.; ARROYO FERNÁNDEZ, A.; PUJOL ROBINAT, A.; XIFRO COLLSAMATA, A.; "Sumisión química y robos en serie". Revista Española de Medicina Legal, nº 39, 2013, pp. 40-41.

82 Vid. en esa línea las SSTS de 16 de noviembre de 1992, 11 de noviembre de 2004, 4 de mayo de 2005.

La STAP de la Coruña de 30 de septiembre de 2011 condena por delito de lesiones respecto de un caso de un hombre, que tras consumir en compañía de otros una infusión queda sin conocimiento, apareciendo horas más tarde en un lugar diferente completamente desorientado. En el reconocimiento médico se encuentran restos de escopolamina en su organismo, y se considera no acreditada la desaparición de unas cantidades de dinero que la víctima llevaba ese día en su vehículo.

83 Vid. STAP Madrid de 27 de septiembre de 2018. 


\section{Conclusiones}

La tipificación expresa del empleo de sustancias tóxicas para provocar la disminución de capacidad de otra persona en orden a someterla a un contacto sexual sin su consentimiento merece una valoración positiva, ${ }^{84}$ pues viene a considerar específicamente la relevancia penal de supuestos diferenciados de la tradicional pérdida de sentido, pues la anulación de la voluntad, se refiere a hechos en los que el autor incide sobre la capacidad intelectual y volitiva de la víctima, lo que supone una forma de facilitar la comisión del delito especialmente taimada. Y en ese sentido, se ha afirmado que: "la configuración de los delitos sexuales mediante sumisión química parece requerir de un especial enfoque valorativo, ya que se trata de un ataque especialmente grave por la alevosía que le es inherente" 85 . A pesar de ello, la regulación llevada a efecto no parece acertada por la particular configuración legal escogida por el legislador y ubicada como una presunción del falta de consentimiento entre los abusos sexuales.

La privación de la capacidad para determinarse en materia sexual es una situación equiparable al empleo de violencia para vencer la oposición a la realización del hecho, y por ello, hubiera merecido su ubicación entre los delitos de agresión sexual. La administración de sustancias que disminuyen la conciencia del sujeto es un procedimiento idóneo para evitar la oposición de la víctima equivalente al empleo de fuerza por lo que, como señalan algunos autores, merecería la misma valoración por parte del Ordenamiento. Y en ese sentido la STAP de Madrid, de 1 de diciembre de 2009 señalaba que: "la administración de sustancia hipnótica de manera subrepticia es un supuesto de violencia, pues se estima que lo decisivo es el resultado de anu-

84 En sentido contrario CANCIO MELIÁ, M.; "Delitos contra la libertad e indemnidad sexuales... cit. p. 33 por considerarlo innecesario al tratarse de hechos incluibles en el supuesto de hecho de abuso sexual de persona privada de sentido.

85 Vid. AGUSTINA, J. R.; PANYELLA CARBÓ, M. N., "Los delitos sexuales...". cit. p. 5. 
lación de consciencia y derivadamente de voluntad de la víctima y no el modo de administración. $Y$ en este sentido el TS ha señalado que el uso de un narcótico es, sin duda alguna, una acción material ejercida sobre el cuerpo de la víctima para privarle del uso de sus facultades físicas y psíquicas, a la vez de conciencia, voluntad y de movimientos, siendo puramente accidental que se use un medio químico (narcótico, gas) en vez de mecánico; el fin perseguido y el resultado alcanzado son los mismos: anular tanto su defensa, como su huida y su petición de socorro; y que la administración de un narcótico que la inmoviliza (tanto o más que si la atara) es una agresión lesiva no inferior al forcejeo, ligaduras, empujones". Sin embargo, a partir de la regulación específica de la sumisión química en el 181.2 como modalidad de abuso sexual se excluye la posibilidad de considerar los supuestos de administración de drogas para facilitar el delito sexual dentro del concepto de violencia propio de la violación por vía interpretativa, como sí hacía la mencionada sentencia cuando aún no se había producido la modificación de $2010^{86}$.

Una adecuada desvaloración de la gravedad del empleo intencional de tóxicos para incapacitar a la víctima aconseja una reforma, que permita una respuesta sancionadora equivalente a la de las agresiones sexuales y la violación, si el hecho acaecido es un acceso carnal o acto equiparado. En tales casos se parte de considerar que la administración deliberada de tóxicos alcanza a doblegar la voluntad de la víctima privándola de toda capacidad de oposición al hecho al que va a ser sometida. Y esa opción de técnica legislativa parece también ser la más acorde al sentido de las directrices establecidas en la Resolución 53/7 de la Co-

86 Muy crítica con la equiparación entre la sumisión química en sentido estricto y la mera vulnerabilidad química a la que conduce la regulación en vigor, impidiendo incluir los casos en los que la sustancia es administrada intencionalmente para cometer el delito sexual entre las agresiones sexuales, equiparándola a la violencia vid. CARUSO FONTÁN, V., "La utilización de psicóticos y narcóticos como medio comisivo del delito de robo con violencia o intimidación". Diario La Ley. n 8061, 2013. Consultado en BD la Ley Doctrina. p. 8 del texto del fichero digital. 
misión de Estupefacientes de Naciones Unidas. Mientras que, si la incapacidad de la víctima es preexistente y no provocada por el que luego va a ser autor del hecho sexual, de manera que quienes actúan se limitan a aprovechar esa situación, en opinión doctrinal mayoritaria, merece una desvaloración distinta y menos grave en atención a que el autor no ha provocado con su actuación la situación de incapacidad de la persona sometida al hecho sexual ${ }^{87}$.

En un enfoque más amplio, contextualizado en el conjunto de los delitos contra la libertad sexual se hace necesario referirse al debate suscitado con motivo de las recientes sentencias dictadas en esta materia, sobre hechos que han sido objeto de una muy amplia cobertura en los medios de comunicación, y han alcanzado a generar una importante movilización social, que reclama más rigor punitivo ${ }^{88}$. Sobre la materia hay varios textos prelegislativos con la finalidad de reformar estos delitos ${ }^{89}$.

87 Dejando para el tipo de abuso sexual las situaciones de vulnerabilidad química, en las que la pérdida de facultades no ha sido provocada por quien después comete el delito. Una propuesta de esas características puede verse en ACALE SÁNCHEZ, M.; "La reforma de los delitos contra la libertad sexual de las mujeres adultas: una cuestión de género". Mujer y Derecho penal ¿necesidad de una reforma desde una perspectiva de género?. Dir. A. Monge Fernández. Barcelona, 2019. p. 249; AGUSTINA, J. R.; MARCOFRANCIA, M. P.; ¿Agresión o abuso sexual?. Cuestiones forenses a propósito del caso "La Manada". Revista Española de Medicina Legal, 2019, p. 1.; FOMBELLIDA VELASCO, L.; "Consideraciones sobre el delito sexual...cit. pp. 4-5; JERICÓ OJER, L; "Perspectiva de género ...cit. p. 331-332.

88 En particular las sentencias por delitos sexuales cometidos en grupo, así las STAP de Navarra de 20 de marzo de 2018, del TS en casación de la anterior de 4 de julio de 2019 que enjuician el conocido caso de "la Manada" y la llamada "Manada de Manresa" en la STAP de Barcelona de 31 de octubre de 2019.

89 El primero de esos textos es la Proposición de ley de protección integral de la libertad sexual y para la erradicación de las violencias sexuales, presentada por el Grupo Parlamentario Confederal de Unidos Podemos, en Comú Podem, En Marea.

El segundo es el Anteproyecto de L. O. de modificación del Código Penal para la protección de la libertad sexual de las ciudadanas y los ciudadanos, por encargo del Ministerio de Justicia a la Sección penal de la Comisión general de Codificación. 
En el análisis del conjunto de delitos contra la libertad sexual atendiendo a la clasificación seguida por el Código penal se ha evidenciado la dificultad de definir el ámbito propio de aplicación de los abusos sexuales consistentes en acceso carnal o modalidades equiparadas del artículo 181.4, pues parece muy difícil imaginar un supuesto de acceso carnal definido como alguna modalidad de penetración por vía vaginal, anal o bucal sin que medie violencia, intimidación y sin consentimiento del ofendido. Los supuestos planteables son los de personas físicamente incapacitadas para poder oponer resistencia, paralíticos, o personas inmovilizadas. Y en tales casos no se alcanza a poder entender una razón para poder justificar la menor sanción penal, en lo que supone una menor protección de sujetos en situación de incapacidad para oponerse a su ofensor o intentar alguna forma de defensa por sí mismos. Y de igual modo sucede con los demás casos de abusos sexuales considerados ex lege como no consentidos del artículo 182.2, de personas en situaciones de incapacidad para prestar consentimiento o de cuyo trastorno mental se abusa.

En cambio, semejantes apreciaciones no son trasladables al abuso sexual genérico del 181.1, que puede encontrar un ámbito propio de aplicación en las actuaciones por sorpresa o amparados en contextos situacionales en los que el ofendido no puede reaccionar por el carácter repentino e imprevisto del hecho y cuenta con una pena adecuada a la diversa entidad de los muy variados hechos, que pueden incardinarse en su tipicidad.

La distinción entre los abusos sexuales sin consentimiento del 181.2 cuando consisten en acceso carnal del 181.4 y la violación, si bien corresponde a una valoración diferenciada conforme a los diversos medios comisivos utilizados para vencer la oposición de la víctima, sin embargo no alcanza a tener un ámbito aplicativo concreto y bien definido, al contrario, en vez

Sobre las propuestas contenidas en tales textos con sentido muy crítico, vid. DÍEZ RIPOLLÉS, J. L.; "Alegato contra un derecho penal sexual identitario". $R E C P C, \mathrm{n}^{\circ} 21$, de 2019, pp. 1-29. 
de una muestra de precisión técnica de la regulación, más bien se presenta como disfuncional. La previsión de una pena menor para los abusos resulta profundamente injusta cuando se trata de hechos sobre personas que se encuentran en una posición que las incapacita física o psicológicamente para oponerse a una conducta sexual no deseada. En tales circunstancias, la distinción punitiva entre violación y abusos sexuales más que corresponderse con una precisa valoración de la distinta gravedad de los hechos en relación a los medios comisivos empleados, evidencia un déficit de protección de potenciales víctimas sin ninguna justificación posible pues, ante la incapacidad para oponerse o intentar alguna forma de defensa por mínima que sea, el atacante no necesita recurrir ni a la violencia ni a la intimidación para consumar el contacto sexual.

En este punto, y en relación con la sumisión química en particular como supuesto equiparado a la privación de sentido, cabe cuestionarse si merece un tratamiento punitivo distinto la sumisión química genuina o proactiva, de la sumisión química oportunista o vulnerabilidad química. Como se ha señalado, la opinión común entre los autores es que sólo la sumisión química causada intencionalmente por quien después lleva a cabo el contacto sexual merece la equiparación al uso de violencia característica de la agresión sexual, en una consideración de que en tal caso hay un mayor desvalor de acción atribuible al autor del hecho, dicho muy gráficamente tan grave como el empleo de fuerza que deja inconsciente es el "puñetazo químico sobre el cerebro". Y coinciden esos autores en admitir la calificación como abuso sexual en los casos de mera vulnerabilidad química, por no haber sido causada por el autor la incapacidad de la víctima $^{90}$.

En cambio, la duda al respecto del tratamiento diferenciado de la sumisión química intencional y la mera vulnerabilidad química se hace patente si el foco de atención se sitúa sobre la necesidad de protección de personas incapaces de reaccionar

90 Vid. Supra nota 87. 
frente al contacto sexual impuesto. Como se ha señalado respecto de las situaciones de incapacidad física o psicológica para un contacto sexual, el tratamiento como abuso y no como violación conlleva establecer una menor protección injustificada a quienes no se encuentran en condiciones de oponerse. Tal incapacidad de oponerse también puede padecerla quien se encuentra bajo los efectos de consumo voluntario de tóxicos, encontrándose en tal caso con una menor protección por parte de la normativa penal. $Y$ con un argumento semejante señala Ragués que se trata de: "una regulación difícilmente justificable si se tiene en cuenta que en los casos de abuso por aprovechamiento de privación de sentido no tiene ninguna relevancia cómo la víctima haya llegado a tal estado" $"$. En cierto sentido, es como si el Ordenamiento asumiera el prejuicio o el estereotipo de si la mujer bebe (o consume otro tipo de tóxicos) se muestra como sexualmente disponible, y en consecuencia le brinda una menor protección haciendo recaer sobre ella la responsabilidad de hacerse merecedora de la tutela del ordenamiento mediante su buena conducta ${ }^{92}$.

Autorizadas voces abogan por la unificación de los accesos carnales inconsentidos del 181.4 en el delito de violación recuperando el contenido de la regulación en términos muy similares a la reforma del año 1989 respecto de la inclusión dentro del mismo del tratamiento de los hechos sexuales acaecidos sobre personas privadas de sentido. Y dicho concepto de violación que es el que parece estar arraigado en el imaginario colectivo. Se argumenta a favor de tal opción, que lo definitorio de la violación es el tratarse de un acceso carnal inconsentido, más allá de los medios empleados para ello ${ }^{93}$. Definición de violación que viene a coincidir con el sentido que el atribuye a ese vocablo el diccionario de la RAE, que se refiere $a$ tener acceso carnal con

91 RAGUES Y VAlleS, R.; Lecciones de Derecho Penal. Parte Especial. Dir. J. M. Silva Sánchez. $6^{\circ}$ Ed. Barcelona, 2019. pp. 138-139.

92 En ese sentido las declaraciones de Faraldo Cabana a El País de 1 de noviembre de 2019 con motivo de la sentencia de la "Manada de Manresa".

93 Vid. en ese sentido De VICENTE MARTÍNEZ, R.; "El delito de violación... cit. pp. 182 y 193. 
alguien en contra de su voluntad o cuando se halla privado de sentido o de discernimiento. Con ello se trataría de hacer coincidir la legislación con el uso común del lenguaje, que tendría el ventajoso e inmediato efecto de acercar la racionalidad jurídica a la sociedad, que percibe las resoluciones judiciales, no sin cierta razón, como alejadas no ya de un cierto sentido de justicia, sino del más mínimo sentido común ${ }^{94}$. En este punto es innegable el potencial simbólico y la importancia de llamar a las cosas por su nombre, al que apelan como argumento no desdeñable varios autores ${ }^{95}$.

No obstante, cabe otra posibilidad si se considera adecuada la actual división de las infracciones contra la libertad sexual, que diferencia distintos niveles de lesividad construidos sobre la entidad del hecho de naturaleza sexual cometido (atentado a la libertad sexual /acceso carnal) y al medio comisivo empleado: violencia o intimidación, falta de consentimiento y consentimiento viciado. Para respetar tal diferenciación de grupos de infracciones, el déficit de protección detectado en los abusos sexuales inconsentidos de los artículos 181.2 y 181.4 cuando consisten en acceso carnal habría de venir corregido con una ampliación del marco penal aplicable a tales hechos, con una superposición parcial de su marco punitivo con él del delito de violación más amplia o extensa de la actualmente existente ${ }^{96}$, pero que, incluso alcanzando eventualmente a la completa equiparación del marco penal de ambas infracciones, carecería del efecto comunicativo de considerar violación el hecho de acceder

94 Muy interesante es la amplia reflexión de Ramírez Ortiz sobre la función comunicativa de los órganos jurisdiccionales en una sociedad saturada de información y a la vez manipulable, vid. RAMÍREZ ORTÍZ, "Sociedad en red... cit. pp. 24-25.

95 Vid. en ese sentido GARCÍA ALBERO, R.; MORALES PRATS, F.; Comentarios a la Parte Especial ... cit. pp. 11-12; LASCURAIÍN SÁNCHEZ, J. A.; "Las huellas... cit. p. 18; JERICÓ OJER, L.; "Perspectiva de género ... cit. p. 330 .

96 En esa dirección la propuesta incluida en el Comunicado sobre la actual regulación de las agresiones y abusos sexuales del Grupo de Estudios de Política criminal, accesible en la página web del GEPC. 
carnalmente sobre una persona incapaz de autodeterminarse, física o psicológicamente, en el ámbito sexual.

Para quienes se han pronunciado a favor de una decisión legislativa de mayor calado cual es la de superar la distinción entre abusos sexuales y agresiones en los términos de fijados por la regulación actual, apuntan a otras razones para la desaparición de la mencionada diferencia. Razones entre las que se cuentan las basadas sobre el significado del lenguaje empleado por el legislador y su efecto simbólico. Abusar, es hacer uso excesivo, injusto o indebido de algo o de alguien, lo que pudiera dar a entender implícitamente que, de los sujetos referidos en el marco de ese conjunto de delitos, cabe un uso posible, o autorizado que queda fuera del abuso ${ }^{97}-\mathrm{y}$ sin que integre a su vez el ejercicio de la libertad sexual de tales sujetos-.

En cualquier caso, hay cierta unanimidad al respecto, en que no parece necesario el aumento de los marcos penales previstos para este grupo de infracciones, que son considerablemente rigurosos e intimidatorios, sin olvidar la imposición preceptiva de la medida de libertad vigilada de cumplimiento posterior a la pena privativa de libertad prevista en el artículo 192.1 del Código Penal, que sólo excepcionalmente permite su imposición discrecional si se trata de un delincuente primario autor de un único delito. Medida de signo marcadamente inocuizador, asentado sobre un modelo de prevención situacional y aplicable en el contexto de un conjunto de infracciones de gran peso simbólico ${ }^{98}$.

Como se ha advertido ya en este trabajo, no se desconoce que la inmensa mayoría de delitos contra la libertad sexual, y en particular los violentos, son cometidos por varones, y un porcen-

97 Sobre el término abuso vid. ASÚA BATARRITA, A.; "El significado de la violencia sexual contra las mujeres y la reformulación de la tutela penal en este ámbito. Inercias jurisprudenciales". Género, violencia y Derecho. Coord. P. Laurenzo y otras. Valencia, 2008. p. 148-149; SAN MIGUEL BERGARECHE, M. N., “¿Juzgar y castigar... p. 26.

98 Vid. SEITÚN, D., El agresor sexual. Peligrosidad y persona consecuencias jurídico penales. Buenos Aires, 2019, pp. 2-3. 
taje muy alto de sus víctimas son mujeres, por ello con razón se ha calificado a tales hechos como una muestra de violencia de género ${ }^{99}$. Y por ello, no cabe desconocer que la perspectiva de género aporta un valioso y extenso marco teórico insustituible para la caracterización de la violencia sexual ejercida sobre las mujeres y su estudio como fenómeno de la realidad criminológica. Y de la caracterización de la delincuencia sexual como violencia de género suelen extraerse una serie de consecuencias materializadas en determinadas exigencias para los poderes públicos, en particular respecto del tratamiento de esta clase de infracciones ${ }^{100}$, de las cuales unas parecen asumibles, y otras cuestionables $^{101}$.

Entre las exigencias asumibles, con matices, cabe destacar las relacionadas con el tratamiento de quienes habiendo sido objeto de un hecho contra su libertad sexual, deciden denunciar y entablar un proceso para la exigencia de responsabilidad penal. En este punto se alude a la necesidad de incorporar la «perspectiva de género» a la formación de los sujetos que in-

99 Como señala LORENTE ACOSTA, "un análisis profundo de las agresiones sexuales nos muestra que se trata de "conductas sexuales que satisfacen necesidades no sexuales", subrayando que el agresor no parte de un deseo de satisfacer un estímulo sexual, sino que lo que de verdad hace es utilizar la relación sexual para vehiculizar la violencia contra las mujeres de manera que pueda conseguir lo verdaderamente trascendente para él, que es la manifestación de poder por medio del ataque y la humillación de la víctima, pues cuanto mayor es el daño que produce, más poderoso y, en consecuencia, más satisfecho se siente. El sexo es el instrumento, el arma, como puede serlo el puño, la patada o el cuchillo". Vid. "Como dioses en el Olimpo. Los agresores sexuales". Meridiam. $\mathrm{n}^{\circ} 33$, 2004. p. 38. (sin cursivas en el original)

100 Sobre las implicaciones de llevar la perspectiva de género al proceso penal vid. SUBIJANA ZUNZUNEGUI, I., "La perspectiva de género en el enjuiciamiento de los delitos de violencia del hombre contra la mujer". Boletín Comisión Penal. $\mathrm{n}^{\mathrm{o}}$ 10, vol, I., 2018. pp. 28-39.

$101 \mathrm{Se}$ ha llegado a hablar de «feminismo punitivo» para referirse a "las movilizaciones, que apelando al feminismo y a la defensa de las mujeres, protagonizan exigencias de criminalización (introducción de nuevos delitos en los ordenamientos jurídicos) y/o aumento de las penas para los delitos ya existentes". Vid. PICHT, T., "Feminismo punitivo". Jueces para la Democracia. n $^{\circ} 92,2018$. p. 44. 
tervienen a lo largo del proceso penal, a fin de evitar la vivencia del acceso a la justicia como un nuevo ataque, esta vez, desde las instituciones, la llamada «victimización secundaria» ${ }^{102}$. No obstante esa incorporación no puede tener lugar en contraposición al conjunto de garantías que configuran el proceso penal ${ }^{103}$. Especial importancia tiene el reconocer los estereotipos, que a veces incluso de manera inconsciente, se filtran en la valoración de la prueba ${ }^{104}$, en la fijación de los hechos o en la calificación jurídica para evitar interpretaciones, que convierten en objeto de investigación a la actitud y el pasado de la denunciante o de una forma $\mathrm{u}$ otra le trasladan la responsabilidad de lo sucedido condicionando el enjuiciamiento ${ }^{105}$. En ese sentido, se alude a la necesidad de formar a los operadores jurídicos -en particular a los miembros del Poder Judicial- en materia de género, lo que ha dado lugar a una reforma de la LOPJ que se orienta en esa dirección, aunque con discutible acierto ${ }^{106}$. La dificultad de tal

102 Sobre la perspectiva de género llevada al derecho penal vid. ACALE SÁNCHEZ, M. "Interpretación judicial del derecho penal desde la perspectiva holística de género". Jueces para la Democracia. n 92, 2018. pp. 26-43.

103 Cautelosos con la idea de trasladar la perspectiva de género al derecho penal vid. VARELA CASTEJÓN, X.; FERNÁNDEZ SUÁREZ, N., "Algunas reflexiones sobre la perspectiva de género". Boletín Comisión Penal. $\mathrm{n}^{\mathrm{o}} 10$, vol., I., 2018. pp. 8-10.

104 Si bien algunos de esos sesgos culturales han desaparecido o tienden a desaparecer, como la exigencia de una resistencia heroica de la mujer sometida a una violación, o llevar un determinado tipo de ropa considerado provocativo, hay que mantenerse alerta frente a prejuicios del tipo de si la mujer ha bebido quiere decir que está sexualmente disponible, u otros análogos. Vid. en ese sentido, LORENTE ACOSTA, M.; “Actuación médico forense... cit. pp. 10-11.

$105 \mathrm{Al}$ respecto, el artículo 25.2 c) del Estatuto de la víctima se refiere a la necesidad de adoptar medidas "para evitar que se formulen preguntas relativas a la vida privada que no tengan relevancia con el hecho delictivo enjuiciado, salvo que el Juez o Tribunal consideren excepcionalmente que deben ser contestadas para valorar adecuadamente los hechos o la credibilidad de la declaración".

106 L. O. 5/2018, de 28 de diciembre, que reforma la LOPJ sobre medidas urgentes en aplicación del Pacto de Estado en materia de violencia de género. Se muestra crítica con los contenidos formativos incorporados, ACALE SÁNCHEZ, M. “Interpretación judicial... cit. pp. 42-43. 
formación es que, más que de transmisión de unos conocimientos de contenido legal establecidos como establece la reforma, el déficit detectado va referido a la necesidad de desarrollar actitudes hacia la denunciante, en el sentido de no admitir estereotipos basados en el género, con la dificultad inherente a un cambio de tal clase.

Siendo necesario evitar estereotipos en la calificación y valoración jurídica de los hechos no lo es menos en la fase probatoria y, en particular, la valoración de la declaración de la denunciante. Conviene recordar que la prueba del supuesto fáctico de la ley penal, tiene lugar mediante un riguroso sistema probatorio presidido por la garantía del principio de presunción de inocencia. Garantía que se considera como un derecho absoluto, lo que exige que la declaración de culpabilidad, sólo pueda tener lugar cuando se consideran probados los hechos objeto de acusación "más allá de toda duda razonable"107. Es conocida la dificultad probatoria de hechos ocurridos sin más personas presentes, que las que después acabarán situadas en la posición de parte acusada y denunciante, como a menudo ocurre en los delitos contra la libertad sexual. De manera que cobra especial importancia la valoración de la declaración de la persona que ha sido víctima de los hechos, y los requisitos exigibles para que pueda ser considerada como prueba de cargo, cuando constituye el único elemento de prueba.

En ese sentido hay que partir de la consideración de la declaración de la denunciante como prueba testifical, de manera que tiene lugar bajo promesa o juramento de decir la verdad, y que en caso de no ser cierta puede generar responsabilidad penal ${ }^{108}$. Al respecto existe una jurisprudencia consolidada sobre los requisitos exigibles al testimonio de la víctima para tener virtualidad suficiente para enervar la presunción de inocencia ${ }^{109}$.

107 LASCURAÍN SÁNCHEZ, J. A.; "Las huellas... cit., p. 17.

108 Con detalle, GISBERT, S., "La declaración de la víctima como prueba de cargo: mitos y mentiras". Revista Libertalia, 5 de octubre de 2019.

109 Entre otras, las STC 347 de 11 de diciembre de 2006, STC 258 de 18 de diciembre de 2007. Y las STS 355 de 28 de mayo de 2015, STS 282 de 13 
De acuerdo con esa doctrina se acude a los parámetros fijados para valorar la fiabilidad, medidos sobre la ausencia de incredibilidad subjetiva, la verosimilitud y persistencia en sostener el testimonio acusatorio, en los mismos términos en los que han de valorarse respecto de cualquier delito respecto del cual sólo exista el testimonio de la víctima como único elemento incriminatorio posible ${ }^{110}$.

En particular, por la dificultad de acreditar la comisión de abusos mediante sumisión química cobra especial valor el informe pericial del forense. La labor de los profesionales de la medicina legal debe enfocarse a acreditar el delito sexual y no únicamente a identificar el tóxico causante de la incapacidad para facilitar la comisión del hecho. De acuerdo con ello, la finalidad de la actuación es la valoración integral de las consecuencias de la actuación sufrida ${ }^{111}$. Y en su informe han de incorporar toda la información disponible, en particular la sintomatología de la víctima compatible con la sumisión química, como indicios en orden a acreditar los hechos ocurridos, que puedan servir para conformar el conjunto de elementos probatorios ${ }^{112}$.

Por último y para concluir, pese a ser la sumisión química una de las últimas incorporaciones a la regulación -en vigor desde 2010-, sin embargo, ha alcanzado a convertirse en uno de los elementos más controvertidos de todo el conjunto normativo de delitos contra la libertad sexual por sintetizar una opción político criminal, que establece diferencias de protección difícilmente justificables y que, inconscientemente, parece trasladar a las

de junio de 2018, STS 119 de 6 de marzo de 2019 y STS 391 de 24 de julio de 2019.

110 De VICENTE MARTÍNEZ, R.; "El delito de violación... cit. pp. 206 ss.; JERICÓ OJER, L.; "Perspectiva de género... cit. pp. 321-322.

111 LORENTE ACOSTA, M.; “Actuación médico forense... cit. pp. 17 y ss.

112 Muy interesante la valoración de la prueba en la STAP de Santiago de Compostela de 6 de marzo de 2014, en el fundamento jurídico primero apartado número 3 , donde analiza todo el conjunto de síntomas que sirven para fundamentar la ingesta de una sustancia idónea para afectar a la capacidad, aún cuando la cantidad de sustancia detectada en los análisis no es indicativa. 
víctimas la responsabilidad de hacerse merecedoras de la tutela penal en determinadas situaciones. Por ello se nos muestra como uno de los elementos más incomprensibles y cuestionados y que apunta a convertirse en uno de los objetos centrales del debate y de futuras reformas.

\section{BIBLIOGRAFÍA}

ACALE SÁNCHEZ, M. "Interpretación judicial del derecho penal desde la perspectiva holística de género". Jueces para la Democracia. $\mathrm{n}^{\circ}$ 92, 2018.

ACALE SÁNCHEZ, M.; "La reforma de los delitos contra la libertad sexual de las mujeres adultas: una cuestión de género". Mujer y Derecho penal ¿necesidad de una reforma desde una perspectiva de género?. Dir. A. Monge Fernández. Barcelona, 2019. https://doi.org/10.2307/j. ctvq2w28r.11

AGUSTINA, J. R.; MARCO-FRANCIA, M. P.; ¿Agresión o abuso sexual?. Cuestiones forenses a propósito del caso "La Manada". Revista Española de Medicina Legal, 2019. https://doi.org/10.1016/j.reml.2019.09.002

ASÚA BATARRITA, A.; "El significado de la violencia sexual contra las mujeres y la reformulación de la tutela penal en este ámbito. Inercias jurisprudenciales". Género, violencia y Derecho. Coord. P. Laurenzo y otras. Valencia, 2008.

BARRUTIA SOLIVERDI, B:, "Estudio de la sumisión química". La Ley Penal. no 117, 2015.

BECERRA-GARCÍA, J. A.; "Epidemiología de la sumisión química". Medicina Clínica , no 9, 2015. https://doi. org/10.1016/j.medcli.2015.02.001

BERTOMEU RUIZ, A.; ARROYO FERNÁNDEZ, A.; PUJOL ROBINAT, A.; XIFRO COLLSAMATA, A.; "Sumisión química y robos en serie". Revista Española de Medicina Legal, $\mathrm{n}^{\mathrm{o}}$ 39, 2013. https://doi.org/10.1016/j. reml.2012.10.006 
BOLDOVA PASAMAR, M. A.; "El nuevo concepto de pornografía infantil: una interpretación realista". Revista Penal, $\mathrm{n}^{\mathrm{o}} 38,2016$.

BRAGE CENDÁN, S., "El delito de abuso sexual facilitado por el uso de sustancias químicas". La Ley, 2013.

BURILLO-PUTZE, G.; LÓPEZ-HERNÁNDEZ, A.; EXPÓSITO-RODRÍGUEZ, M.; DUEÑAS-LAITA, A.; "Sumisión química, oportunista o premeditada". Medicina Clínica, $\mathrm{n}^{\circ}$ 140, 2013. https://doi.org/10.1016/j. medcli.2012.05.035

CANCIO MELIÁ, M.; "Los delitos de agresiones sexuales, abusos sexuales y acoso sexual". La Ley, 2001.

CANCIO MELIÁ, M.; "Una nueva reforma de los delitos contra la integridad sexual". La Ley Penal. no 80, 2011.

CANCIO MELIÁ, M.; "Delitos contra la libertad e indemnidad sexuales". Memento Penal. Edición actualizada a julio de 2019, consultada en BD QMementix.

CARMONA SALGADO, C., Curso de Derecho Penal Español. Parte Especial I. Madrid, 1996.

CARUSO FONTÁN, V., "La utilización de psicóticos y narcóticos como medio comisivo del delito de robo con violencia o intimidación". Diario La Ley. n ${ }^{\circ}$ 8061, 2013.

CRUZ-LANDEIRA, A.; QUINTELA-JORGE, O.; LÓPEZRIVADULLA, M.; "Sumisión química: epidemiología y claves para su diagnóstico". Medicina Clínica, $\mathrm{n}^{\circ} 20$, 2008. https://doi.org/10.1016/S0025-7753(08)75505-2

CUERDA ARNAU, M. L.; "Agresión y abuso sexual: violencia o intimidación vs. consentimiento viciado". La Manada. Un antes y un después en la regulación de los delitos sexuales en España. Valencia, 2018.

CUGAT MAURI, M., "Delitos contra la libertad e indemnidad sexuales". Comentarios a la Reforma Penal de 2010. Valencia, 2010.

De VICENTE MARTÍNEZ, R.; "El delito de violación: problemas que plantea su vigente redacción". La Manada. Un antes y un después en la regulación de los delitos 
sexuales. Dirs. Acale Sánchez, Faraldo Cabana, Valencia, 2018.

DÍAZ Y GARCÍA CONLLEDO, M., TRAPERO BARREALES, M. A., "La "edad de consentimiento sexual" en la reforma del Código Penal de 2015". Estudios de Derecho Penal. Homenaje al Prof. Miguel Bajo. Coord. S. Bacigalupo Sagesse. Madrid, 2016.

DÍEZ RIPOLLÉS, J. L.; “Alegato contra un derecho penal sexual identitario". RECPC, $\mathrm{n}^{\circ}$ 21, 2019.

FARALDO CABANA, P.; "Evolución del delito de violación en los códigos penales españoles. Valoraciones doctrinales". La Manada. Un antes y un después en la regulación de los delitos sexuales. Dirs. Acale Sánchez, Faraldo Cabana, Valencia, 2018.

FARALDO CABANA, P.; RAMON RIBAS, E.; "La sentencia de la Manada y la reforma de los delitos de agresiones y abusos sexuales”. Dirs. Acale Sánchez, Faraldo Cabana, Valencia, 2018.

FARALDO CABANA, P.; "Hacia una reforma de los delitos sexuales con perspectiva de género". Mujer y Derecho penal ¿necesidad de una reforma desde una perspectiva de género?. Dir. A. Monge Fernández. Barcelona, 2019. https://doi.org/10.2307/j.ctvq2w28r.12

FOMBELLIDA VELASCO, L.; "Consideraciones sobre el delito sexual facilitado por sustancias". La Ley, 2013.

GARCÍA-CABALLERO, C.; CRUZ-LANDEIRA, A.; QUINTELA-JORGE, O.; "Sumisión química en casos de presuntos delitos contra la libertad sexual analizados en el Instituto nacional de Toxicología y Ciencias Forenses (Departamento de Madrid) durante los años 2010, 2011 y 2012”. Revista Española de Medicina Legal, n 40, 2014. https://doi.org/10.1016/j.reml.2013.07.003

GARCÍA CABALLERO, C.; QUINTELA, J.; CRUZ LANDEIRA, A.; "Alleged-drug facilitated sexual assault in a Spanish population sample". Forensic Chemistry, 2017. https://doi.org/10.1016/j.forc.2017.02.009 
GARCÍA-REPETTO, R.; SORIA, M. L.; "Sumisión química: reto para el toxicólogo forense", Revista Española de Medicina Legal, $\mathrm{n}^{\circ}$ 37, 2011. https://doi.org/10.1016/ S0377-4732(11)70072-4

GARCÍA REPETTO, R.; SORIA, M. L.; "Consideraciones toxicológicas sobre supuestos casos de sumisión química en delitos de índole sexual en el sur de España entre los años 2010-2012”. Revista Española de Medicina Legal, n 40, 2014. https://doi.org/10.1016/j.reml.2013.06.003

GARCÍA RIVAS, N.; Derecho Penal Español. Parte Especial I. Dir. F. J. Álvarez García. Valencia, 2011.

GAVILÁN RUBIO, M., “Agresión sexual y abuso con prevalimiento: análisis de la reciente jurisprudencia". Revista de Derecho, Empresa y Sociedad. n 12, 2018.

GIMBERNAT ORDEIG, E.; "Prólogo a la décima edición". Código Penal. Tecnos. 25 . ed. Madrid, 2017.

GISBERT, S., "La declaración de la víctima como prueba de cargo: mitos y mentiras". Revista Libertalia, 5 de octubre de 2019.

GÓMEZ TOMILLO, M.; "Derecho penal sexual y reforma legal. Análisis desde una perspectiva político criminal". RECPC, 2005.

JERICÓ OJER, L.; "Perspectiva de género, violencia sexual y Derecho penal". Mujer y Derecho penal ¿necesidad de una reforma desde una perspectiva de género?. Dir. A. Monge Fernández. Barcelona, 2019. https://doi.org/10.2307/j. ctvq2w28r.13

LASCURAIIN SÁNCHEZ, J. A.; Vid. "Las huellas de La Manada". El Cronista del Estado Social y Democrático de Derecho. $\mathrm{n}^{\circ} 77,2018$.

LÓPEZ-MUÑOZ, F.; "Pócimas de bruja en la literatura del Siglo de Oro español: la otra cara de los agentes terapéuticos y psicotrópicos". Revista Medicina, 39. 2017.

LORENTE ACOSTA, M.; "Como dioses en el Olimpo. Los agresores sexuales”. Meridiam. $\mathrm{n}^{0}$ 33, 2004. 
LORENTE ACOSTA, M.; "Actuación médico forense en la atención a las víctimas de agresiones sexuales por sumisión química". Ponencia presentada en Curso "Agresiones facilitadas por el uso de sustancias químicas". Centro de Estudios Jurídicos del Ministerio de Justicia. Madrid, 2013.

MARTÍN LORENZO, M.; Ley Orgánica, 5/2010. Memento Experto Francis Lefevre. Madrid, 2010.

MORALES PRATS, F.; GARCÍA ALBERO, R.; Comentarios a la Parte Especial del Derecho Penal. 10a. Ed. Cizur Menor, 2016.

MUÑOZ CONDE, F.; “La vinculación del juez a la ley y la reforma de los delitos contra la libertad sexual. Algunas reflexiones sobre el caso "La Manada". Revista Penal, $\mathrm{n}^{\mathrm{o}} 43,2019$.

ORTS BerengueR, E.; Derecho Penal. Parte Especial. Coord.. J. L. González Cussac. 5a Ed. Valencia, 2016.

PANYELLA CARBÓ, M. N.; AGUSTINA, J. R.; "Sumisión química $v s$. vulnerabilidad química: análisis criminológico de los delitos sexuales facilitados por el uso de sustancias psicoactivas a partir de una muestra de sentencias". Revista Española de Investigación Criminológica, $\mathrm{n}^{\circ}$ 17, 2019.

PANYELLA CARBÓ, M. N.; AGUSTINA, J. R.; "Los delitos sexuales facilitados mediante el uso de sustancias psicoactivas: análisis jurídico-penal de la denominada "sumisión química". Revista Política Criminal. (en prensa)

PÉREZ ALONSO, E.; “Concepto de abuso sexual: contenido y límite mínimo del delito de abusos sexuales". In Dret. $n^{\circ} 2019$.

PICHT, T., "Feminismo punitivo". Jueces para la Democracia. $n^{\circ}$ 92, 2018.

QUERALT JIMÉNEZ, J. J.; Derecho Penal Español. Parte Especial. $7^{\text {a }}$. Ed. Valencia, 2015.

RAGUES Y VALLES, R.; Lecciones de Derecho Penal. Parte Especial. Dir. J. M. Silva Sánchez. 6a. Ed. Barcelona, 2019. 
RAMÍREZ ORTÍZ, "Sociedad en red, igualdad, proceso y derecho penal. La sentencia de la Manada". Jueces para la Democracia. $\mathrm{n}^{\circ}$ 92, 2018.

SANCHO DE SALAS, M.; XIFRÓ COLLSAMATA, A.; BERTOMEU RUÍZ, A.; ARROYO FERNÁNDEZ, A.; "Sumisión química con finalidad sexual: nuevos aspectos legales". Revista Española de Medicina Legal, nº 38, 2012. https://doi.org/10.1016/j.reml.2012.02.002

SAN MIGUEL BERGARECHE, M. N., “¿Juzgar y castigar con perspectiva de género?”. Boletín Comisión Penal. n ${ }^{\circ}$ 10, vol., II., 2018.

SUBIJANA ZUNZUNEGUI, I., "La perspectiva de género en el enjuiciamiento de los delitos de violencia del hombre contra la mujer". Boletín Comisión Penal. n 10, vol, I., 2018.

TAMARIT SUMALLA, J. M.; "Los delitos sexuales. Abusos sexuales. Delitos contra menores (arts. 178, 180, 181, 183, 183 bis)". La Reforma Penal de 2010: análisis y comentarios. Cizur Menor, 2010.

TORRES, Y.; ALER, M.; PLATA, A.; DOMÍNGUEZ, A.; SANZ, P., GISBERT, M.; "Factores que afectan al análisis biológico de las muestras de agresiones sexuales". Cuadernos de Medicina Forense, no 13, 2007. https://doi. org/10.4321/S1135-76062007000100005

VARELA CASTEJÓN, X.; FERNÁNDEZ SUÁREZ, N., "Algunas reflexiones sobre la perspectiva de género". Boletín Comisión Penal. $\mathrm{n}^{\mathrm{o}}$ 10, vol., I., 2018.

VEGA GARCÍA, A.; "Agresiones facilitadas por el uso de sustancias químicas: retos y realidades". Ponencia presentada en Curso "Agresiones facilitadas por el uso de sustancias químicas”. Centro de Estudios Jurídicos del Ministerio de Justicia. Madrid, 2013.

XIFRÓ, A.; BARBERÍA, E.; PUJOL, A.; "Sumisión química con finalidad sexual en el laboratorio forense", Revista Española de Medicina Legal, $\mathrm{n}^{\circ}$ 40, 2014. https://doi. org/10.1016/j.reml.2014.04.001 